\title{
Aznalcóllar dam failure. Part 2: Stability conditions and failure mechanism
}

\author{
A. GENS* and E. E. ALONSO*
}

An analysis of the conditions that led to the failure of the Aznalcóllar dam is made in the paper. Pore water pressures prevailing in the foundation clay at the time of the failure have been established on the basis of piezometric observations made after the failure. A simplified consolidation analysis is first presented to interpret pore water pressure generation and dissipation and to evaluate the evolution of shear stresses along the potential failure plane. Both limit equilibrium and finite element analysis are used to back-analyse the failure and to derive representative strength parameters along the failure surface. Three-dimensional effects introduced by the layered nature of the foundation clay are then described. They provide an explanation for the location of the slide, which affected only the south-eastern portion of the embankment. The failure is examined in the final part of the paper from the perspective offered by the current knowledge of the strength behaviour of brittle clays. The significance of progressive failure is discussed, together with other factors that played a significant role in this case: the homogeneous nature and very low permeability of the foundation clay and the natural state of the clay, probably affected by some initial damage, which reduced the available strength along bedding planes.

KEYWORDS: clays; dams; plasticity; pore pressure
Cet exposé donne une analyse des conditions qui ont conduit à la rupture du barrage d'Aznalcóllar. Nous avons établi les pressions d'eau interstitielle existant dans l'argile de fondation au moment de la rupture en nous basant sur les observations piézométriques réalisées après la rupture. Nous présentons tout d'abord une simple analyse de consolidation pour interpréter l'apparition et la dissipation de pressions d'eau interstitielle le long du plan de rupture potentiel et pour évaluer l'évolution des contraintes de cisaillement le long du plan de rupture potentiel. Nous utilisons à la fois des analyses d'équilibre limite et d'élément fini pour rétro-analyser la rupture et pour dériver des paramètres représentatifs de la résistance le long de la surface de rupture. Nous décrivons ensuite les effets tridimensionnels causés par la nature stratifiée de l'argile de fondation. Ces effets nous donnent une explication quant à l'emplacement du glissement qui a affecté uniquement la portion sud-est du remblai. Dans la partie finale de cet exposé, nous examinons la rupture avec les connaissances actuelles sur le comportement de résistance des argiles friables. Nous étudions la signification de la rupture progressive ainsi que d'autres facteurs qui ont joué un rôle significatif dans ce cas : la nature homogène et la très faible perméabilité de l'argile et l'état naturel de l'argile, probablement affecté par quelques dégradations initiales qui ont réduit la résistance disponible le long des plans de stratification.

\section{INTRODUCTION}

The failure of the Aznalcóllar dam and additional background information covering the geotechnical properties of the materials involved has been described in a companion paper (Alonso \& Gens, 2006). Field observations were interpreted with the help of laboratory experimental information. The failure was described in Alonso \& Gens (2006) as a translational motion of the rockfill dam, which slid on a bedding plane of a homogeneous high-plasticity Miocene carbonate clay ('Guadalquivir blue marl'). The brittle nature of the clay strength suggested that progressive failure could play a significant role in reducing the available foundation strength during the construction of the dam.

Further insight into the conditions and processes that eventually led to the failure are presented in this paper, which is the second in a series of three. The starting point is a review of the hypothesis and results of the stability calculations performed at the design stage, carried out in 1978 and reviewed in 1996, two years before the failure. Then additional field data concerning measured pore water pressures in the clay formation after the failure are pre-

Manuscript received 8 March 2005; revised manuscript accepted 29 November 2005

Discussion on this paper closes on 2 October 2006, for further details see p. ii.

* Department of Geotechnical Engineering and Geosciences, Universitat Politècnica de Catalunya, Barcelona, Spain. sented. They provide fundamental information for the interpretation of the failure mechanism.

Different calculation approaches, described in the paper, provide complementary views on the mechanisms involved. A consolidation analysis of the foundation clay during the history of the dam and lagoon construction provides insights into the rupture mechanisms. The results of conventional limit equilibrium and elasto-plastic finite element analysis are described. The three-dimensional effect of clay layering is also analysed in order to explain the actual location of the failure. The features that favour the development of progressive failure in the clay foundation are then reviewed in the context of previous work performed on this subject. The paper concludes with a discussion of the main reasons leading to the failure. They are placed in perspective by comparing them with the assumptions made in design.

\section{STABILITY CALCULATIONS AT THE DESIGN STAGE}

The dam was initially designed in 1978. A representative cross-section of the initial design is shown in Fig. 1. A small upstream embankment is first constructed. Then a bentonitecement wall, which penetrates into the blue clay, is built to provide an impervious barrier. The dam was to be built in phases of increasing height, advancing in the downstream direction. The structure is actually a rockfill dam with an upstream impervious blanket of low-plasticity red clay. This blanket is connected with the vertical cement-bentonite upstream diaphragm wall. Upstream and downstream slopes 


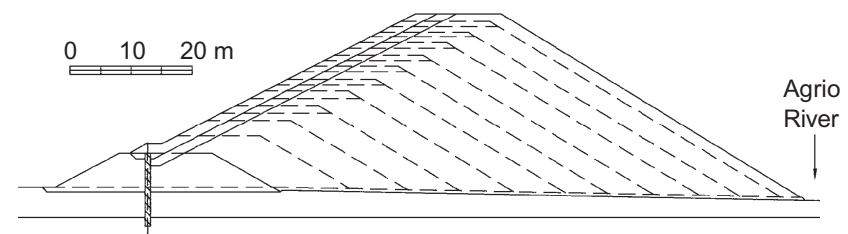

Fig. 1. Original dam design

were defined in the original project as $1 \mathrm{~V}: 1.9 \mathrm{H}$ and $1 \mathrm{~V}: 1.75 \mathrm{H}$ respectively $\left(27.8^{\circ}\right.$ and $29.9^{\circ}$ with respect to the horizontal).

The dam design was checked by standard procedures. A slope stability program, using the Morgenstern-Price method and circular sliding surfaces, was employed to estimate the stability of the dam and the reservoir tailings against a critical downstream failure, as shown in Fig. 2. The following assumptions were made.

(a) The analysis was performed for embankment dimensions corresponding to the maximum envisaged dam height $(30 \mathrm{~m})$.

(b) The tailings were assumed to be fully liquefied. The hypothesis was that the design earthquake could liquefy the high-porosity, fully saturated tailings. Therefore no strength was assigned to the portion of the potential failure surfaces crossing the liquefied pyrite tailings. A unit weight of $30 \cdot 1 \mathrm{kN} / \mathrm{m}^{3}$ was assigned to them.

(c) Earthquake conditions were imposed by means of a pseudo-static procedure. The accelerations considered were $0.048 \mathrm{~g}$ in the horizontal direction and $0.976 \mathrm{~g}$ in the vertical direction. They correspond to an earthquake of magnitude $7 \mathrm{MSK}$.

(d) Water pressures in the foundation and in the dam were said to correspond to steady-state conditions. A review of the computer records allowed an interpretation of this statement. Fig. 2 shows the position of the 'phreatic level' assumed in the analysis. This was a general level, defining the pore water pressures in all materials present (tailings, alluvial sands, lower clay and the dam itself). The selected phreatic level connects the free water level in the deposit with a natural water level at the toe of the dam, which is assumed to coincide with the ground surface.

The stability analyses were conducted in drained conditions using no effective cohesion intercepts for any of the materials. A drained friction angle, $\phi^{\prime}=25^{\circ}$, was assumed for the blue clay, which was the material essentially controlling the stability. The strength parameters for the blue clay were derived from undrained triaxial tests performed on specimens recovered from boreholes and in one trench (block sample).

The critical failure circle was found to be a deep circle, shown in Fig. 2. A safety factor $F=1.30$ computed for this circle was deemed to be acceptable because it was higher than the recommendation $(F=1 \cdot 2)$ of the seismic code applied.

The dam actually built did not follow all the design specifications. A representative cross-section of the failed dam is shown in Fig. 3. A significant change was introduced in 1985, when the downstream slope increased from the projected value of $30^{\circ}(1 \mathrm{~V}: 1 \cdot 75 \mathrm{H})$ to $39^{\circ}(1 \mathrm{~V}: 1 \cdot 24 \mathrm{H})$. The downstream slope was maintained unchanged thereafter. A second significant change took place in 1990: the width of the crest of the dam increased from the planned value of $14 \mathrm{~m}$ to $36.50 \mathrm{~m}$. At that time, the height of the crosssection was $21 \mathrm{~m}$ over foundations. Other changes, which may be identified by comparing Figs 1 and 3, are of minor significance. In 1990 the width of the base of the dam reached a maximum value of $130 \mathrm{~m}$. Subsequent changes in dam height did not modify this base width.

In 1996 the safety of the dam was reviewed to evaluate the possibility of raising the final height of the dam by $2 \mathrm{~m}$. A new but very limited soil exploration was conducted. The main objective of four new boreholes was to determine the characteristics of the dam materials and to find the position

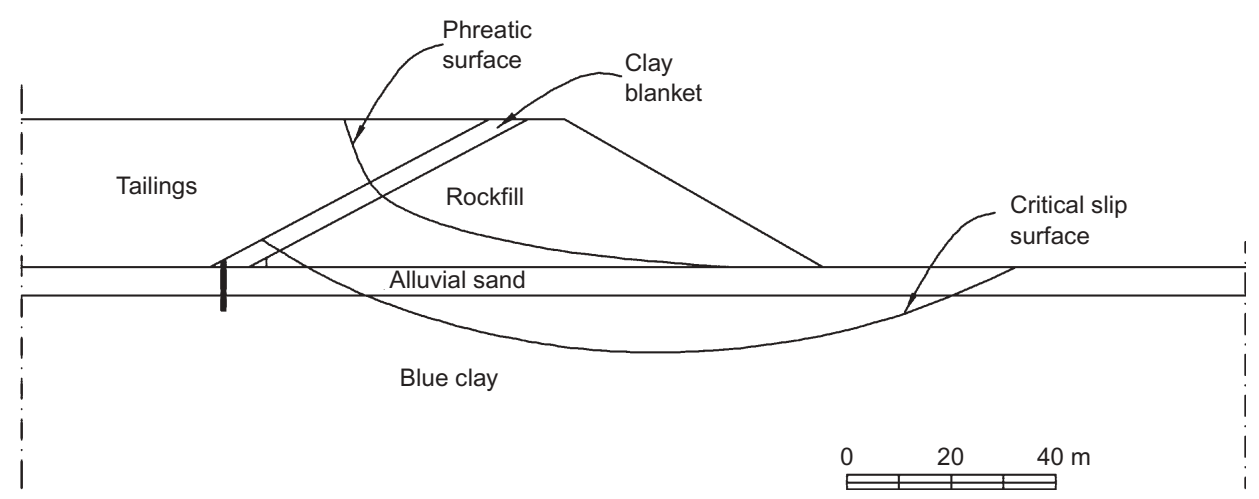

Fig. 2. Estimation of stability conditions at design stage

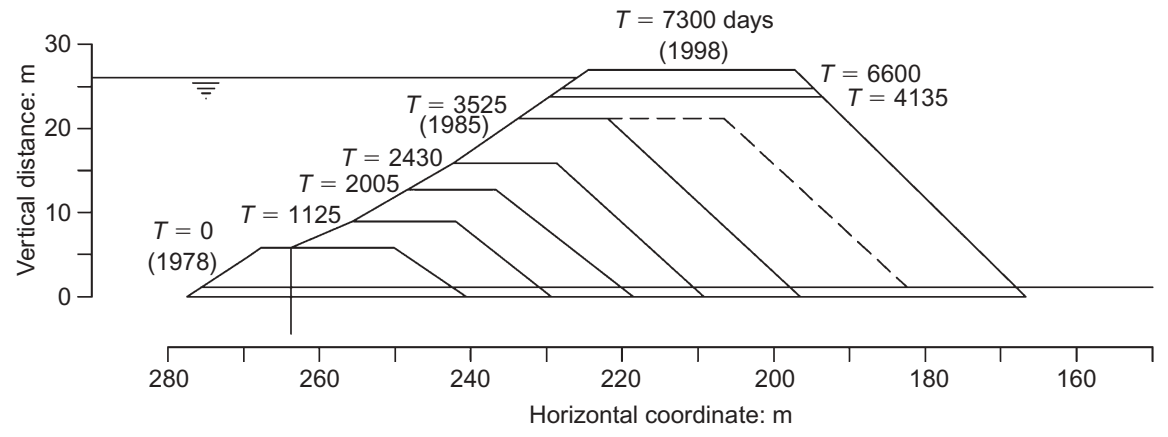

Fig. 3. Evolution of representative cross-section of the dam actually built (east side) 
of the water table. Only one of the boreholes penetrated $5.5 \mathrm{~m}$ into the clay. Two clay samples were taken, and an open tube indicated a free water level $0.5 \mathrm{~m}$ below the rockfill-alluvial contact. These data were interpreted as an indication of a safe situation of the dam, and a 'realistic' horizontal water level at the position indicated by the open tube was defined for the dam.

A stability analysis was again performed for the updated geometry of the dam. The hypotheses made were essentially the same as those described for the original design. Minor changes were introduced in the drained soil properties. Two global phreatic levels were defined: a 'high' one and a 'low' one. The high level was equal to the level defined for the original project (Fig. 2), and it was judged as too conservative. The low level was considered closer to actual conditions. The drained strength parameters were modified: the friction angle was reduced to $\phi^{\prime}=22^{\circ}$, but an effective cohesion $c^{\prime}=20 \mathrm{kPa}$ was introduced. A modified Bishop method was used this time in stability calculations. For the 'low' and 'high' phreatic levels safety factors of 1.31 and $1 \cdot 17$ were calculated.

Despite the reasonably high safety factors computed and the conservative assumptions made (liquefied tailings, earthquake accelerations), the dam failed in the absence of any earthquake. The reasons for this failure are explored in this paper. At the end of the paper the significance of some of the assumptions made at the design stage will be considered again from the perspective offered by the analyses described in the paper.

PORE WATER PRESSURES IN THE FOUNDATION CLAY

Fifteen vibrating wire piezometers were installed in boreholes drilled after the failure. Readings started in April-May 1999 and rapid equilibration, in general, followed (Fig. 4). Piezometer sensors were located in $1 \mathrm{~m}$ long sections of the corresponding boreholes, filled with saturated sand. The

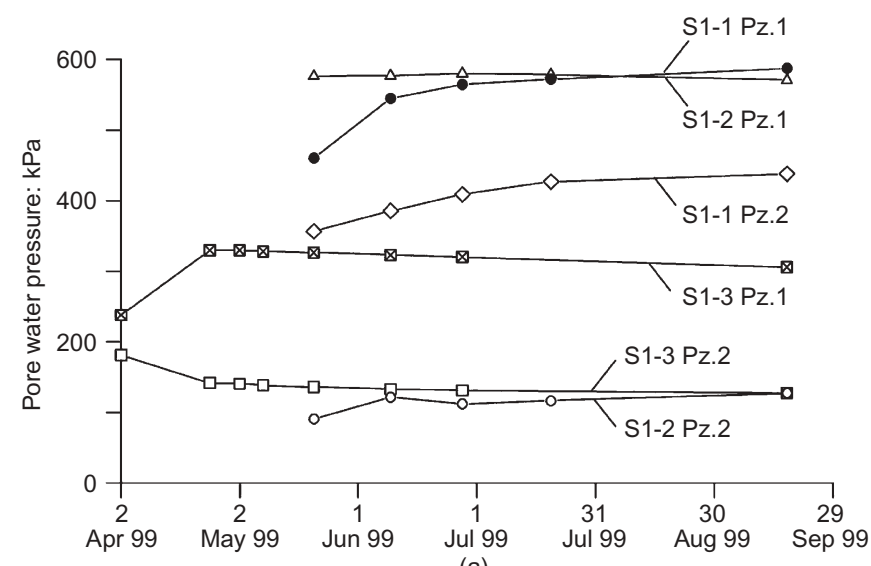

(a)
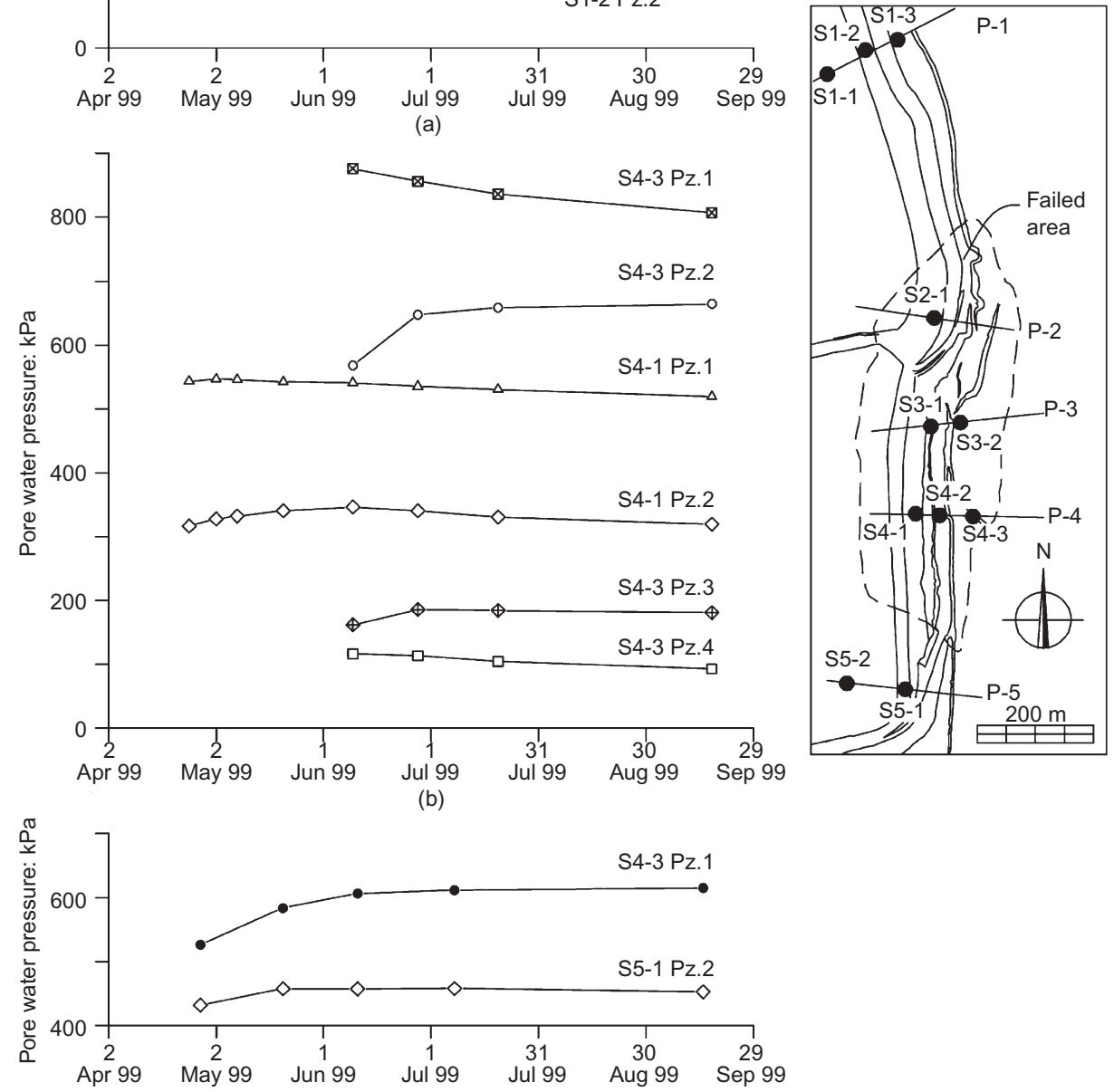

(c)

Fig. 4. Evolution of pore water pressure in piezometers located at different depths in boreholes corresponding to: (a) Profile 1; (b) Profile 4; (c) Profile 5 
remaining length of the borehole was sealed with a cementbentonite mixture.

Pore water pressures measured in September 1999 are shown in Figs 5 and 6 for Profiles 4 and 1. The locations of the instruments (P1, P2, etc.) are shown in these two figures. The most characteristic result was the high pressure measured in the foundation clay. Profile 4 (Fig. 5) is located in the displaced embankment, and the measured pore water pressures cannot be interpreted in a straightforward manner because they are a consequence of a series of events, as follows

(a) the initial pore water pressures, before the failure, which were controlled by the history of embankment construction and the process of pore pressure dissipation

(b) the increment of pore water pressure due to the rapid loading induced by the displaced embankment

(c) the dissipation that had occurred since the failure on 25 April 1998, presumably under changed boundary conditions.

On 25 April 1998 the embankment moved to its new position. raising the load of foundation points such as P1 in Borehole S-4.1 (Fig. 5). The point, therefore, experienced an undrained loading followed by a period of dissipation under newly formed boundary conditions. Other points, such as P2 in the same borehole, probably travelled with the moving dam, but were affected by the rapid unloading associated with the sudden decrease of the tailings level in the lagoon. This sequence of events makes any prediction exercise somewhat uncertain. Perhaps the major difficulty is the correct interpretation of the drainage boundaries after the development of the sliding surface in the proximity of the piezometers.

Piezometers were installed in the vicinity of the sliding surface with the purpose of deriving the pore water pressure conditions at the time of failure. It is clear from Fig. 5 that high pore water pressures, much higher than the values considered in the design, were present in the embankment foundation before the failure. Given the similarities in foundation conditions, Profile 1, located in the non-failed portion of the embankment $400 \mathrm{~m}$ north of the breach (Fig. 6), may offer a more direct insight into the pore water pressures existing at the time of failure in the slide area. For Profile 1, data were available upstream of the embankment, in the centre of the embankment and at the downstream toe of the embankment. Profiles of water pressure across the embankment can be plotted (Fig. 6). This time the interpretation is more straightforward because the only significant change, from the date of the failure, was a partial unloading of the upstream level of tailings and the reduction of hydrostatic pressure in the lagoon.

It is interesting to note in Fig. 6 that the readings in the piezometers $\mathrm{P} 2$, located in a shallower position within the clay, detect the boundary water pressure upstream and downstream of the cut-off wall. Water pressures in the alluvial granular soil downstream of the embankment appear to have a low value, close to the original ground surface, similar to that measured in open tube piezometers. Upstream of the cut-off, the water level in the alluvium is given by the water level in the lagoon, and this explains the reading in piezometer P2 in borehole S1-1. It is also clear that strong vertical pressure gradients exist below the embankment in the vicinity of the position of the sliding surface (in the failed embankment) as a result of the consolidation process

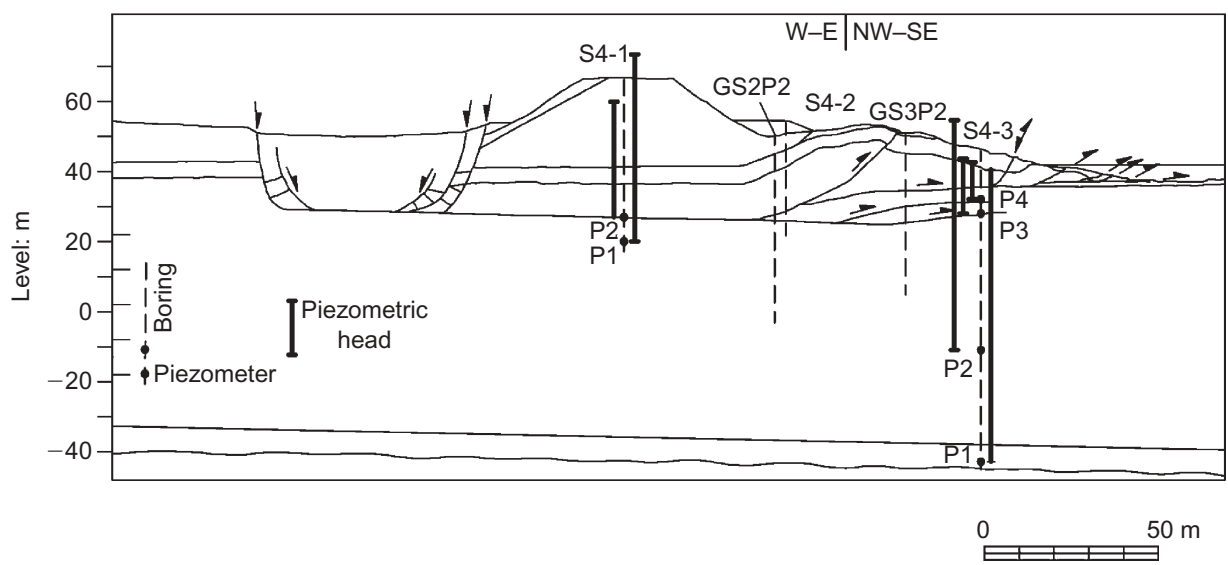

Fig. 5. Pore water pressure measured in piezometers located in Profile 4 (in borings S4-1 and S4-3). Other borings indicated helped to identify the position of sliding surfaces, shown in the plot. The graph also shows the soil profile and the geometry of the displaced dam after failure

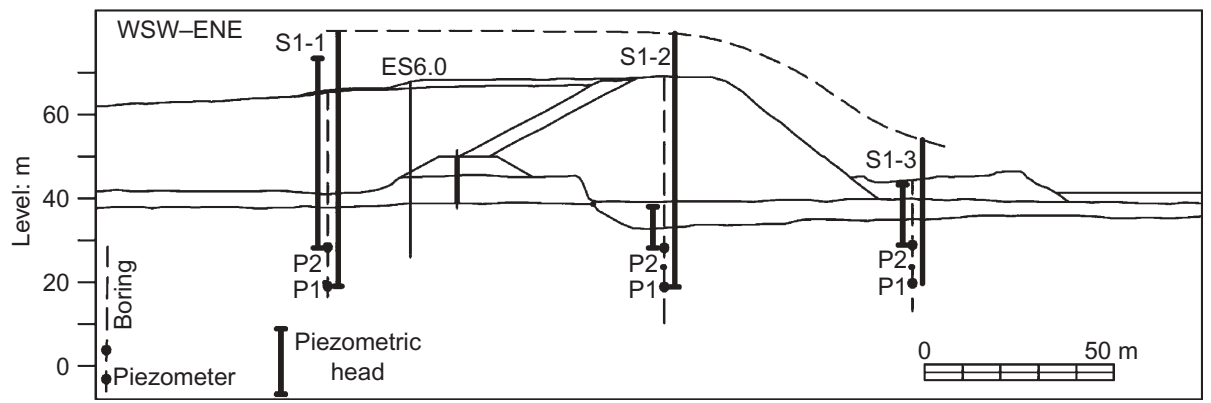

Fig. 6. Pore water pressures measured in piezometers located in borings S1-1, S1-2 and S1-3 in Profile 1 (not affected by the failure). The graph shows also the level of tailings after the failure and the soil profile 
in very impervious clay. These data will be interpreted with the help of a consolidation model described in the next section.

\section{SIMPLIFIED CONSOLIDATION ANALYSIS OF THE CONSTRUCTION PROCESS \\ Estimation of pore water pressures at time of failure}

The measured pore pressures in Profile 1 provide an excellent opportunity to establish reliable estimates of foundation water pressures at the time of failure. If the measurements given in Fig. 6 can be reproduced, then the same calculation procedure can be extended to the conditions prevailing before failure in the slipped embankment. A simple consolidation analysis was developed using the following set of criteria.

(a) Stresses in the subsoil were calculated through an available analytical expression for embankment loading on elastic soil (Poulos \& Davis, 1974). By means of a superposition of incremental loadings, the actual pattern of embankment construction could be followed. The actual sequence of geometrical changes in the embankment was introduced as a set of instantaneous changes in geometry at given times.

(b) Every instantaneous application of loading generates a field of pore water pressures, which has been made equal to the increment of total mean stress. This is considered to be a sufficiently good approximation because, in the undrained triaxial tests reported in Alonso \& Gens (2006), an average value of Skempton's coefficient $A=0.33$ was found.

(c) One-dimensional consolidation in the vertical direction towards the upper alluvium and the lower confined aquifer is applied to every increment of loading. Water levels in the upper alluvium change suddenly at the position of the cut-off wall from lagoon level (upstream of the cut-off) to the ground surface (downstream of the cut-off).

(d) At every instant of time, pore water pressures are calculated as a superposition of all the consolidation processes assumed in the 'discretisation' of the history of embankment construction.

The procedure outlined was coded for the computer and checked against classical theoretical results for one-dimensional consolidation. Distributions of total and effective stresses and water pressures in the clay foundation were calculated at various times during the life of the embankment. It is believed that the distribution of water pressures in the upper levels of the clay is essentially controlled by the dissipation of excess pore pressures towards the upper alluvium (this will be demonstrated later when a comparison is made of water pressures calculated on the failure surface by this simplified procedure, and water pressures derived from a two-dimensional finite element calculation). The method developed was fast and easy to use and provided a good understanding of the pore water and stress changes taking place in the foundation clay during the construction of the embankment and tailings lagoon. It also constituted an efficient base for performing back-analysis of the observed piezometer readings.

Figure 7 shows the evolution of the embankment at the failed section and the sequence of loading increments adopted in the calculations. The same history of dam elevation applies, with minor variations, to Profile 1, within the unfailed embankment, north of the breach. Data in Figs 3 and 7 define the developing geometry of the embankment from January 1978 to the time of failure, in April 1998. The level of tailings followed the embankment height, the level

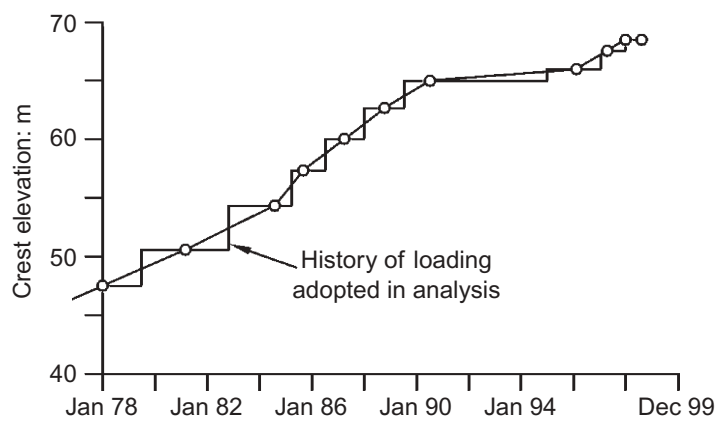

Fig. 7. History of dam construction in terms of elevation of crest and incremental sequence used in calculations

in the lagoon being maintained approximately $1 \mathrm{~m}$ below the crest of the embankment.

The actual changes in natural specific weight of the tailings stored in the north lagoon were taken into account in order to analyse Profile 1 . The natural specific weight of the embankment was calculated assuming the following properties of the dumped shale rockfill: void ratio $e=0 \cdot 4$; specific weight of solids $\gamma_{\mathrm{s}} / \gamma_{\mathrm{w}}=2 \cdot 7$; and degree of saturation $S_{\mathrm{r}}=0 \cdot 3$.

A comparison of the calculated and measured pore water pressures under the embankment and the lagoon, for Profile 1 , is shown in Fig. 8. The calculation simulated the construction process defined in Figs 3 and 7, as well as the reduction in tailings level due to erosion immediately after the failure, the change in boundary condition upstream of the cut-off wall, and the subsequent dissipation time prior to the pore water pressure measurements being performed.

The level of tailings after failure is shown in Fig. 8. It implies an unloading (which was assumed to be undrained) with respect to the tailings level immediately before failure. Fig. 8 shows the calculated pore pressures along the failure plane for two values of $c_{\mathrm{v}}\left(10^{-3} \mathrm{~cm}^{2} / \mathrm{s}\right.$ and $2.3 \times 10^{-3}$ $\mathrm{cm}^{2} / \mathrm{s}$ ) and a comparison with measurements in piezometers P1. Also shown in the figure are the calculated and measured vertical profiles of water pressure at the location of boreholes S1-1, S1-2 and S1-3. They show a strong pore pressure gradient in the upper part of the clay deposit. The agreement between calculated and measured pore pressures is very good for a value of $c_{\mathrm{V}}$ close to $10^{-3} \mathrm{~cm}^{2} / \mathrm{s}$. Remarkably, this back-calculated value is very close to the $c_{\mathrm{V}}$ values derived from consolidation tests on specimens of blue clay (Alonso \& Gens, 2006). This agreement is a further indication of the massive and homogeneous nature of the foundation clay. The back-calculated values are of the same order of magnitude as those derived by Vaughan \& Walbancke (1973) from observation of cutting slopes in London clay.

The next step in the calculations was the estimation of pore water pressures under the embankment and lagoon for a representative profile of the southern part of the east embankment. A change in the vertical density of the deposited tailings was considered. The evolution of pore water pressures at three points under the embankment, in a horizontal plane, $14 \mathrm{~m}$ below the ground surface, is shown in Fig. 9. Also shown in the figure is the estimated crossprofile of pore water pressure immediately before failure for the indicated horizontal plane (which is very close to the position of the actual basal sliding plane). This calculation shows that the pore pressures on the failure plane prior to failure were high, certainly much higher than the values assumed in design.

The plots in Fig. 9 also indicate that pore pressures reached a peak at $t=4500$ days, around 1990, at the end of a relatively rapid increase in embankment height (Figs 3 and 


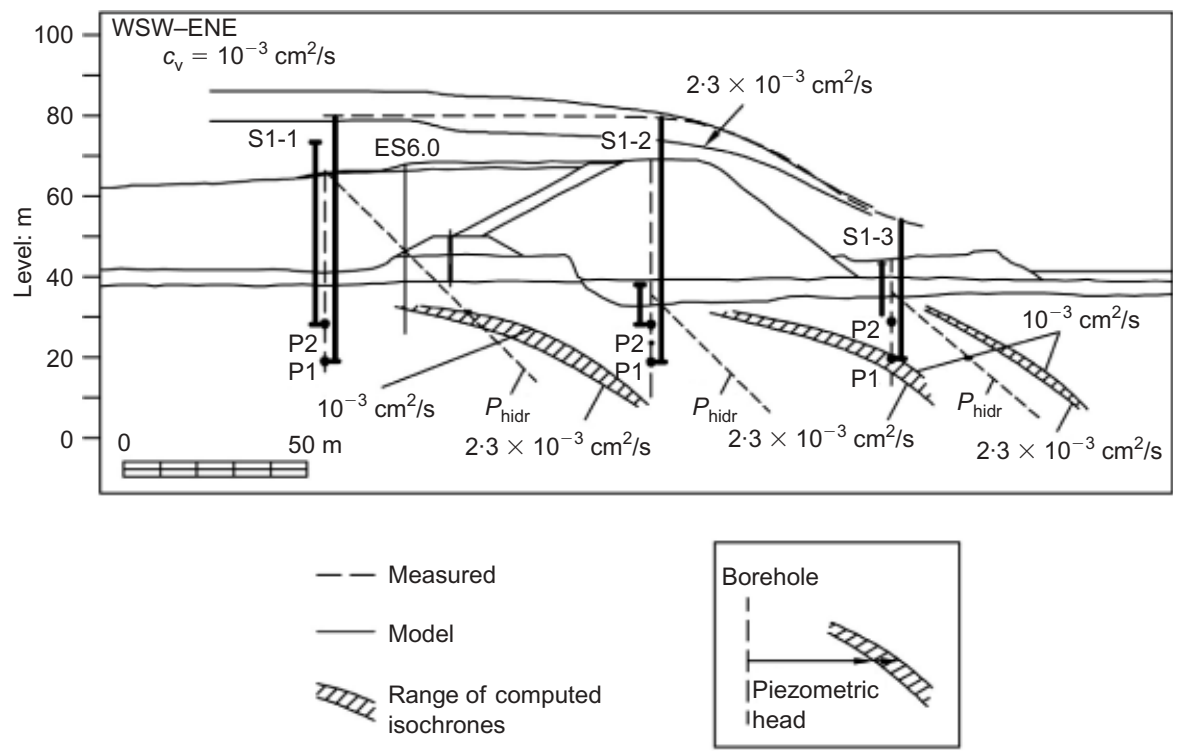

Fig. 8. Calculated and measured distributions of pore water pressures under Profile 1
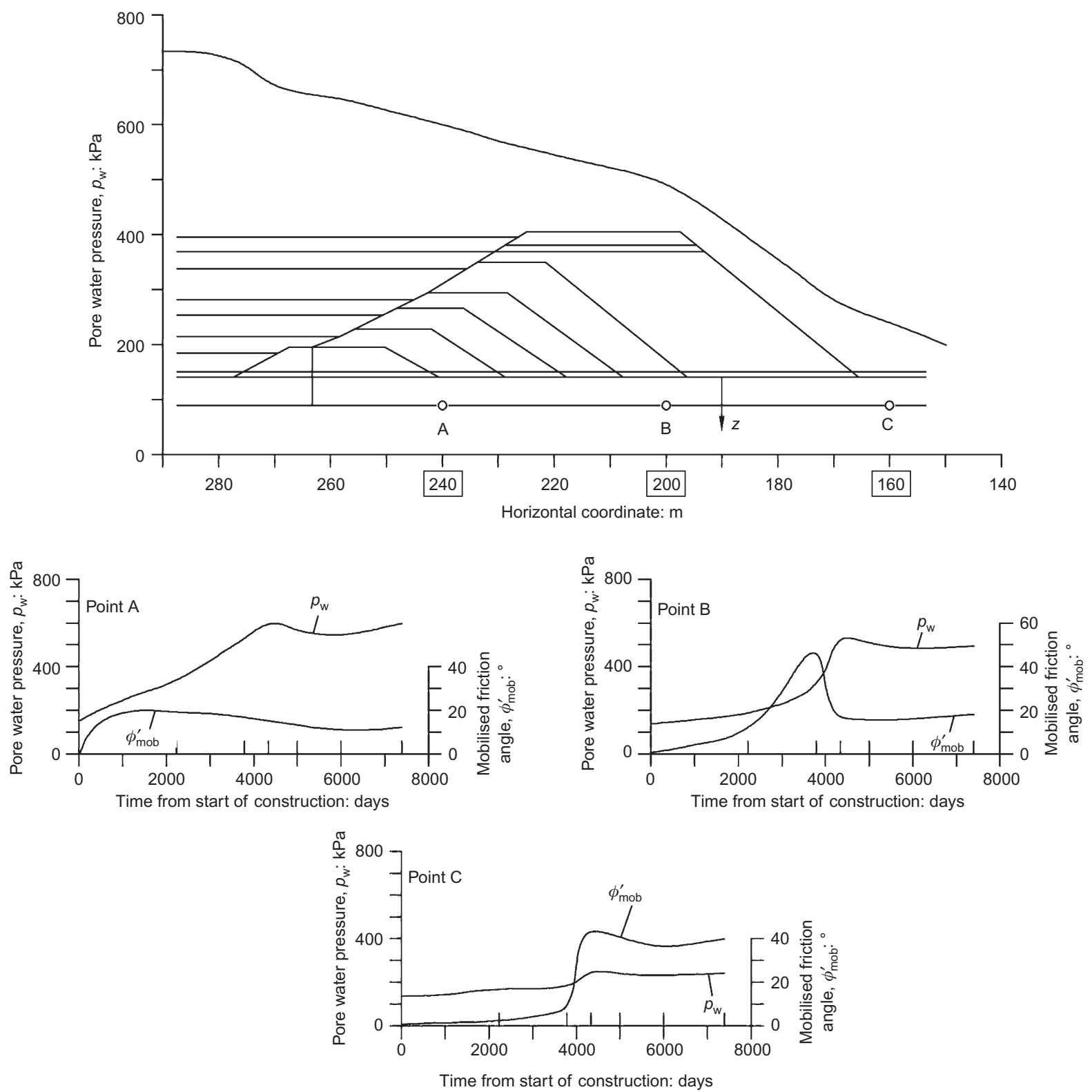

Fig. 9. Calculated water pressures and stress ratios under dam and lagoon at points $\mathrm{A}, \mathrm{B}$ and $\mathrm{C}$ in representative profile of failed southern part of east embankment 
7). The subsequent slowdown in construction rate resulted in a reduction in pore water pressures followed by a final increase associated with the final and faster stages of embankment construction.

\section{Stress ratios}

Shear stress $\tau$ and effective normal stresses $\sigma_{\mathrm{n}}^{\prime}$ were also calculated, on the basis of the elastic stress distributions and the current pore water pressures, on horizontal planes and, in particular, on the position of the future failure plane. The ratio $\tau / \sigma_{\mathrm{n}}^{\prime}$ has been plotted (as a mobilised friction angle) in Fig. 9 for the points selected for representing pore pressures. Also indicated is the calculated absolute value of $\tau$ for a few time values. The mobilised friction angle increases rapidly as the downstream toe of the advancing embankment approaches the point under consideration. As the embankment advances further, the mobilised friction angle decreases because of the increasing 'confinement', which implies a decrease in shear stress and a parallel increase in normal stresses. As time elapses, the dissipation of pore pressures also results in an increase of the effective normal stresses. In this way, an advancing peak of mobilised friction follows the forward construction of the embankment. This is clearly shown in Fig. 10, where the successive profiles of mobilised friction angle along a horizontal plane $(z=14 \mathrm{~m})$, very close to the position of the failure plane, are plotted.

Note that the maximum values are high $\left(35-45^{\circ}\right)$. If the subhorizontal bedding planes do not have an effective cohesion, the advancing embankment has certainly induced some damage on the bedding planes, which are unable to resist those high stress ratios. Note also that a maximum stress ratio was reached at a time $t \cong 3800-4000$ days (around 1988-1989), 10 years before the failure. Later, the dissipation of pore pressures, associated with slower construction rate, led to an increase in normal effective stresses and to a reduction of the stress ratio.

Further insight into the stress changes experienced by the foundation clay is gained if the complete distribution of stress ratios on horizontal planes is plotted for different stages of embankment construction. This is shown in Fig. 11 for three heights of the embankment $(10 \mathrm{~m}, 19 \mathrm{~m}$ and $27 \mathrm{~m})$.
A remarkable result is that the stress ratio reaches a peak at a certain depth within the clay. This is a consequence of the variation of pore pressures, controlled by the clay consolidation, and the distribution of shear stresses below the embankment toe. The depth of the maximum $\tau / \sigma_{\mathrm{n}}^{\prime}$ increases as the height of the embankment increases. For $H=10 \mathrm{~m}$ the maximum $\tau / \sigma_{\mathrm{n}}^{\prime}$ is found for $z=10 \mathrm{~m}$. It increases to $z=12 \mathrm{~m}$ and $z=17 \mathrm{~m}$ when $H=19 \mathrm{~m}$ and $H=27 \mathrm{~m}$. This result indicates the position of the sliding plane, which developed later, as the peak in mobilised friction generates the maximum damage in clay strength. In fact, the brittle behaviour of the clay, and the strength data already reported (Alonso \& Gens, 2006), can be now invoked to advance a qualitative interpretation of the failure mechanism. If bedding planes do not exhibit any effective cohesion, a maximum effective friction angle of around $25^{\circ}$ may be assumed for them. Then, in view of Figs 9, 10 and 11 , the strength on a critically located bedding plane was exceeded for the first time, when the embankment had a height of $8-10 \mathrm{~m}$. This initial critical point was located at a depth of about $z=10 \mathrm{~m}$ under the downstream toe of the embankment.

This was the situation as early as 1980-1981. Additional stressing in the following years could not be resisted in some areas of the clay. The brittle nature of the clay allowed additional straining in the vicinity of the critical points in a typical progressive failure mechanism. The forward construction of the embankment resulted, therefore, in an increasing extension of the area affected by progressive failure. The line plotted in Fig. 11(c) joins the points of maximum stress ratio. It is viewed as a first approximation of the position of the failed surface under the embankment. Its position is quite close to the position of the future failure plane. The inclination of this line has probably helped to concentrate critical conditions on a specific bedding plane. The line thus defined is an approximation to the failed or damaged surface immediately before failure.

These results should be regarded with caution: the actual distribution of mobilised friction angles cannot possibly be the distribution shown in Figs 10 and 11 because, at any point in the clay, the stress ratio is limited first by its peak strength, and then by the reduced friction angles in subse-

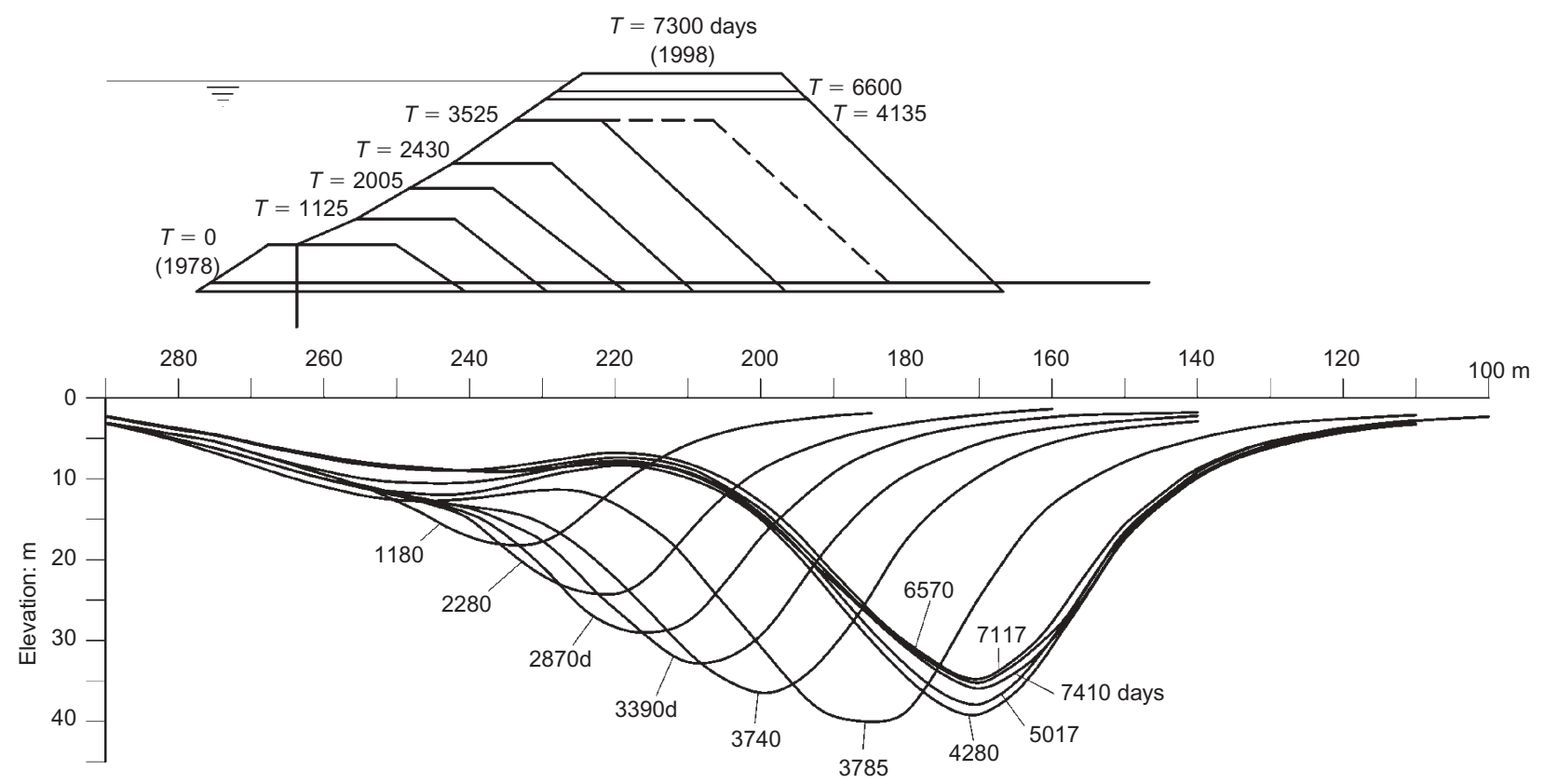

Fig. 10. Variation of mobilised friction in a horizontal plane located at depth $z=14 \mathrm{~m}$ within clay foundation. Numbers indicate time elapsed (days) since start of dam construction (January, 1978) 


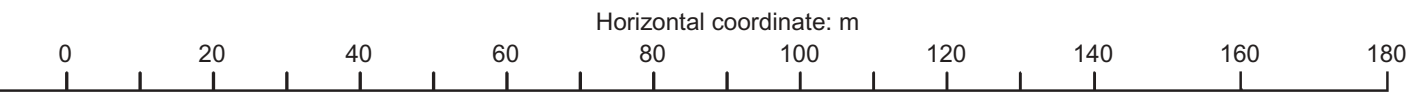

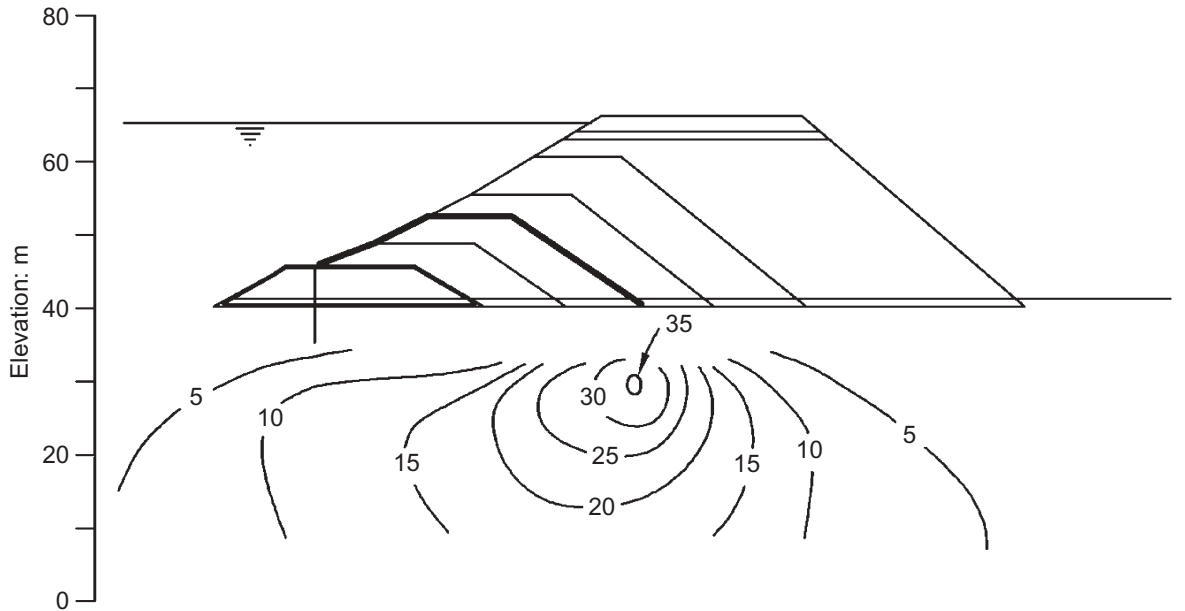

(a)

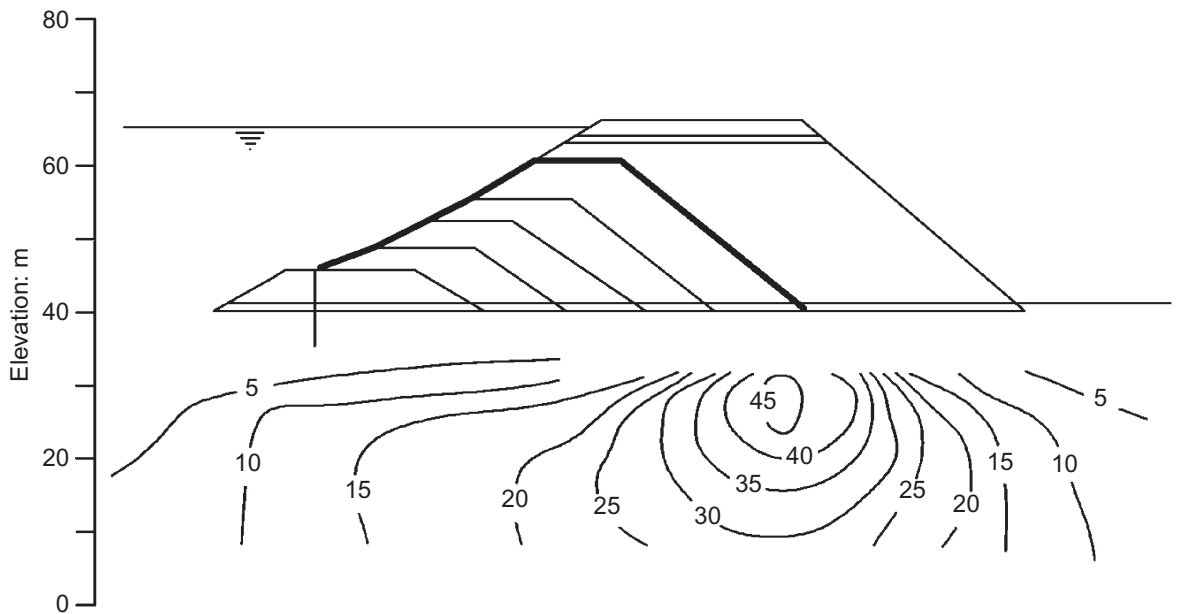

(b)

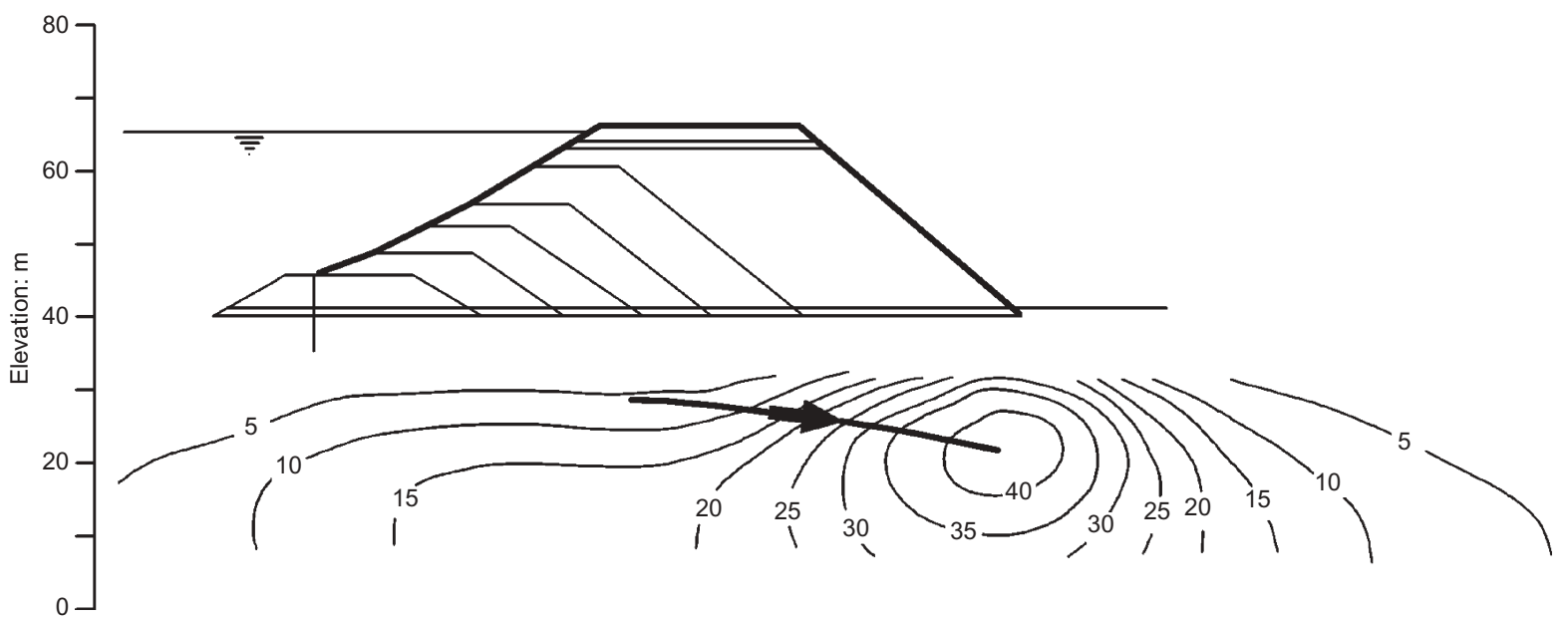

(c)

Fig. 11. Contours of equal mobilised friction on horizontal planes for three phases of construction, in terms of dam height: (a) $H=10 \mathrm{~m}$; (b) $H=19 \mathrm{~m}$; (c) $H=27 \mathrm{~m}$. The line with the arrow in (c) shows the locus of the maximum mobilised angle of shearing resistance

quent stages of straining. But it is believed that this simplified analysis developed in terms of elastic solutions and consolidation theory provides an interesting interpretation of the damage mechanisms that presumably took place before the actual final failure. It provides also a reasonable explanation for the position of the future failure surface.
The downstream construction of the embankment also implies a progressive shear unloading of the bedding planes at any given time, which changes with the position of the point in the clay. This is indicated by the shear stress values shown in Fig. 9. For instance, the points under the crest of the embankment (horizontal distance $x=200-220 \mathrm{~m}$ in the 
figure) experience a reduction of $\tau$ from a maximum of $\tau=$ $100 \mathrm{kPa}$ down to values of $33-46 \mathrm{kPa}$. The absolute value of shear stresses mobilised in the clay is not particularly high. In the failure plane, for the maximum height of the embankment, calculated $\tau$ values are lower than $130 \mathrm{kPa}$.

Maximum $\tau$ values along horizontal planes are always located under the toe of the embankment. Shear stresses increase with depth below the failure plane, unlike the stress ratio, which is also controlled by the pore water pressures.

\section{LIMIT EQUILIBRIUM ANALYSIS}

Despite their limitations, several limit equilibrium analyses were performed with the purpose of gaining additional information on the failure mechanism. In addition, they provide a useful link with engineering practice. Two stability methods were used: Simplified Bishop, for circular surfaces, and Morgenstern-Price, for more general cases. The consolidation analysis reported previously was used to approximate the distribution of pore water pressures in the upper levels of the foundation clay. The impervious cut-off affects the distribution of pore water pressures because it controls the boundary conditions for the dissipation of excess pore water pressures. The program SLOPE/W was used in all cases. The geometry used for the embankment immediately before failure is shown in Fig. 12. A free level of water, $0.5 \mathrm{~m}$ in thickness, exists over the tailings level. The clay is divided into a number of horizontal layers to facilitate the definition of different pore water pressure profiles. The water level in the upper alluvium is given by a phreatic level located at the top surface. The rockfill of the dam is fully drained. Soil properties are given in Table 1.

\section{Back-analysis of failure}

If the actual position of the failure surface is analysed, a drained friction angle of the clay, $\phi^{\prime}=17^{\circ}$, leads to failure conditions (safety factor $\mathrm{SF}=1.007$ ). This friction angle, intermediate between the peak friction angle in direct shear tests $\left(24^{\circ}\right)$ and the residual value $\left(11^{\circ}\right)$, is a first indication of the existence of progressive failure.

In one of the analyses performed, the Agrio river meander was introduced, modifying the geometry downstream of the embankment. For $\phi^{\prime}=17^{\circ}$ a value of $\mathrm{SF}=0.987$, very
Table 1. Soil properties used in limit equilibrium analysis

\begin{tabular}{l|c|c|c}
\hline Soil & $\begin{array}{c}\text { Specific weight: } \\
\mathrm{kN} / \mathrm{m}^{3}\end{array}$ & $\begin{array}{c}\text { Drained friction } \\
\text { angle: degrees }\end{array}$ & $\begin{array}{c}\text { Effective } \\
\text { cohesion }\end{array}$ \\
\hline Tailings & 31 & 37 & 0 \\
Red clay & 21 & 27 & 0 \\
Rockfill & 20 & 40 & 0 \\
Alluvium & 20 & 35 & 0 \\
\cline { 2 - 4 } Blue clay & $19 \cdot 5$ & \multicolumn{2}{|c}{ Variable } \\
\hline
\end{tabular}

close to 1 , was computed. It was concluded that the meander had a very limited effect in the development of the failure.

The minimum safety factor for the embankment is found, however, for critical surfaces other than the quasi-horizontal basal plane. In fact, if circular failure surfaces are assumed, a minimum value $\mathrm{SF}=0.72$ is found for $\phi^{\prime}=17^{\circ}$. If the safety factor is fixed at $\mathrm{SF}=1$, then $\phi^{\prime}$ increases to $\phi^{\prime}=$ $21.5^{\circ}$ for the most critical deep failure circle. This is a further indication that the failure was significantly controlled by progressive failure phenomena and structural conditions as discussed above.

Additional analyses were performed by assuming that the clay had a built-in critical bedding plane (in the actual position of the failure plane) with a reduced strength. The rest of the clay maintains its matrix properties. The combinations of strength in both the critical plane and the clay mass which lead to $F=1$ are shown in Table 2 .

\section{Stability during construction}

The early period of construction (1978-1990) was also analysed. Pore pressures were estimated by means of the procedure described previously. Safety factors were calculated for a horizontal failure surface $10 \mathrm{~m}$ under the top of the clay unit. They are collected in Table 3.

It is interesting to realise that the minimum safety factor is not achieved at the time of failure but at an earlier time, when the embankment had a height of about $21 \mathrm{~m}$, around 1988, just before the large increment of width shown in Fig. 3. An equivalent result is obtained if one examines the friction angles for equilibrium, also shown in Table 3. These results may seem surprising. They indicate that, given a

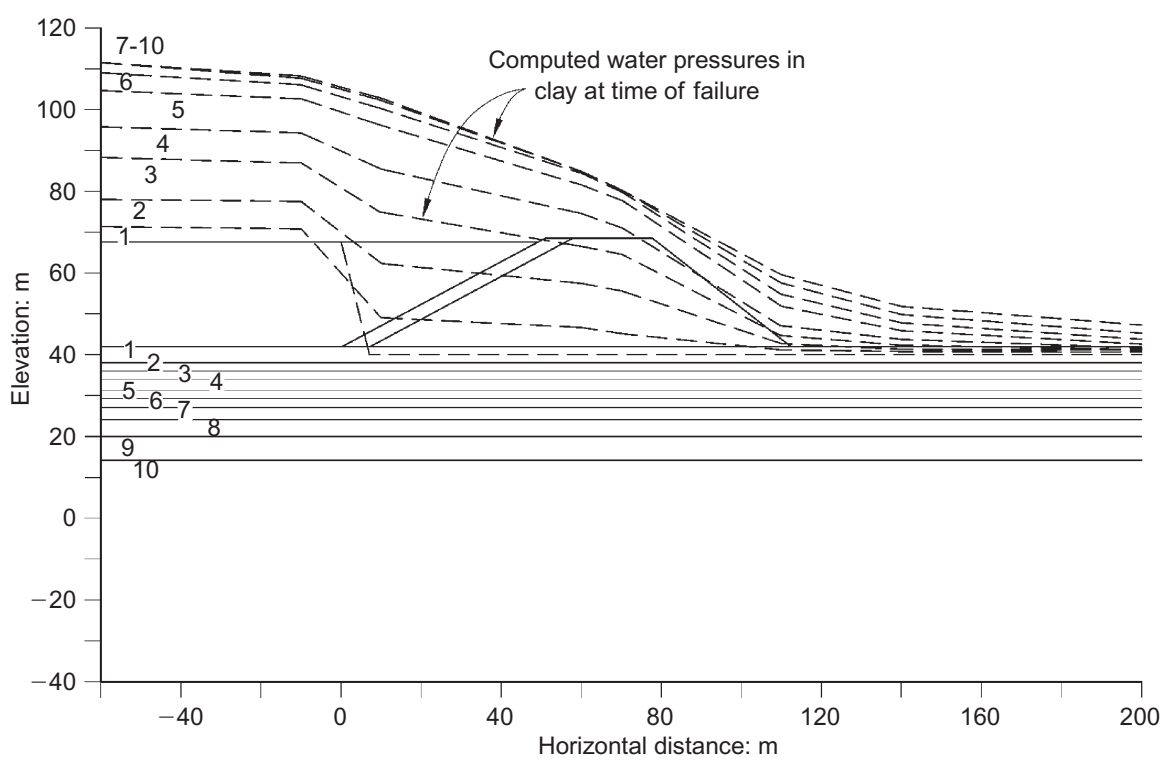

Fig. 12. Embankment geometry and pore water pressures used in limit equilibrium calculations 
Table 2. Drained strength parameters that led to critical stability conditions of the dam. Built-in critical bedding plane. Limit equilibrium analysis

\begin{tabular}{l|c|c}
\hline \multicolumn{2}{l|}{ Clay mass } & Critical bedding plane \\
\hline$c^{\prime}: \mathrm{kPa}$ & $\phi^{\prime}:$ degrees & $\phi^{\prime}:$ degrees \\
\hline 65 & 24 & $12 \cdot 5$ \\
40 & 24 & $13 \cdot 5$ \\
20 & 24 & $14 \cdot 5$ \\
0 & 24 & $15 \cdot 5$ \\
0 & 17 & 17 \\
\hline
\end{tabular}

constant value of the clay friction angle, failure should have taken place in 1988. A similar result, in terms of the maximum mobilised stress ratio along the potential failure surface, was also found in the stress analysis reported before (Fig. 9 and associated discussion). These results are interpreted as providing an additional indication that progressive failure has played an important role in the development of the instability. Available shear strength must have reduced since 1988, probably as a result of the accumulation of deformations along the failure surface, due to the construction of the embankment. It is also implied that no preexisting low-strength failure surface could possibly exist, as in that case failure would have been taking place many years before the actual event. It is, however, likely that the dam has been close to critical conditions during a good part of its construction period.

\section{FINITE ELEMENT ANALYSIS}

Elasto-plastic coupled flow-deformation analyses were performed with the purpose of increasing the understanding of the mechanisms leading to failure. In a first analysis a homogeneous clay deposit was considered. The process of dam construction and tailings impoundment was simulated in 11 steps. Each step was, in turn, divided into an undrained application of loading and a subsequent partial dissipation of the pore pressures until the next undrained unloading is applied. A total of 21 stages of calculation are thus defined. A Mohr-Coulomb elastic perfectly plastic model was adopted for all materials. Material parameters are given in Table 4. The program Plaxis (2-D) was used in all cases.

If peak strength parameters are adopted for the clay $\left(c^{\prime}=\right.$ $64 \mathrm{kPa} ; \phi^{\prime}=24^{\circ}$ ) no plastic points are calculated for the future rupture zone during the whole construction process. It is concluded that, in order to explain the embankment failure, some zones within the clay exhibited reduced strengths. In order to simulate a failure, a progressive reduction of strength parameters is introduced. In this way, the rupture mechanism shown in Fig. 13 is found (contours of equal shear strains are represented). A circular failure is predicted (as in the limit equilibrium type of analysis for homogeneous clay properties).

In a second type of analysis a discontinuity with reduced strength characteristics was located at the position of the sliding plane. The mesh has now 3184 elements and 6565 nodes. This is an interesting problem because, if the reduced parameters chosen reproduce the final conditions, failure is predicted at a much earlier date (in phase 11, out of a maximum of 21). This result is consistent with previous findings, both in the simplified consolidation analysis and in the limit equilibrium calculation. It was necessary to adopt two sets of parameters: a 'more resistant' set for the first part of the analysis, and a 'weaker' set for subsequent calculations. This is not a procedure to simulate progressive failure, but it provides a strong indication of the need to reduce the available strength of the clay if the actual rupture mechanism is to be approximated. The following strength parameters were adopted for the analysis with a discontinuity plane.

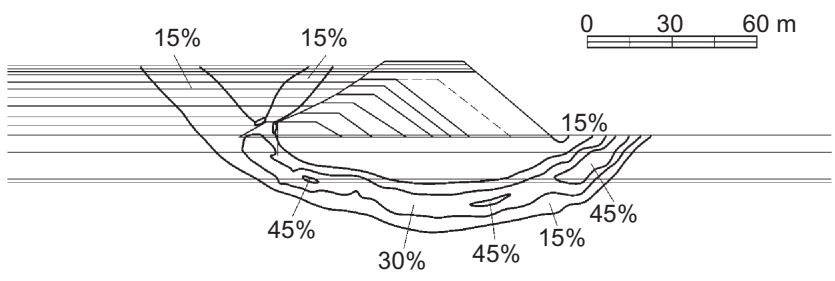

Fig. 13. Contours of equal shear strain calculated at failure in a 2-D elasto-plastic finite element analysis: homogeneous clay

Table 3. Stability for intermediate phases of dam construction

\begin{tabular}{l|c|c|c|c}
\hline $\begin{array}{l}\text { Height of } \\
\text { embankment: } \mathrm{m}\end{array}$ & $\begin{array}{c}\text { Time since origin of } \\
\text { construction: days }\end{array}$ & $\begin{array}{c}\text { SF for } \phi^{\prime}=17^{\circ} \\
\text { in clay }\end{array}$ & $\begin{array}{c}\text { Friction angle in clay for } \\
\text { strict equilibrium: degrees }\end{array}$ & Observations \\
\hline $12 \cdot 8$ & 2220 & $1 \cdot 06$ & 16 & - \\
$21 \cdot 15$ & 3740 & $0 \cdot 89$ & $19 \cdot 5$ & Worst conditions \\
$23 \cdot 5$ & 4280 & 0.98 & $17 \cdot 5$ & - \\
27 & 7300 & 1 & 17 & Actual failure \\
\hline
\end{tabular}

Table 4. Material properties for $\mathrm{FE}$ analysis (Mohr-Coulomb)

\begin{tabular}{|c|c|c|c|c|c|}
\hline Symbol & Alluvial & Clay & Rockfill & Tailings & Units \\
\hline $\begin{array}{l}\gamma_{\mathrm{d}} \\
\gamma_{\text {wet }} \\
E \\
v \\
c^{\prime} \\
\phi^{\prime} \\
\psi \\
\text { Type } \\
k\end{array}$ & $\begin{array}{c}20 \\
20 \\
20 \times 10^{3} \\
0.3 \\
1 \\
35 \\
0 \\
\text { Drained } \\
1.554 \times 10^{-3}\end{array}$ & $\begin{array}{c}21 \\
21 \\
40 \times 10^{3} \\
0.3 \\
\text { Variable } \\
\text { Variable } \\
0 \\
\text { Undrained } \\
1.55 \times 10^{-6}\end{array}$ & $\begin{array}{c}20 \\
20 \\
40 \times 10^{3} \\
0.3 \\
- \\
- \\
- \\
\text { Drained } \\
1.55 \times 10^{-3}\end{array}$ & $\begin{array}{c}31 \\
31 \\
3 \times 10^{3} \\
0 \cdot 3 \\
1 \\
37 \\
0 \\
\text { Drained } \\
1.55 \times 10^{-3}\end{array}$ & $\begin{array}{c}\mathrm{kN} / \mathrm{m}^{3} \\
\mathrm{kN} / \mathrm{m}^{3} \\
\mathrm{kPa} \\
- \\
\mathrm{kPa} \\
\circ \\
\circ \\
- \\
\mathrm{m} / \text { day }\end{array}$ \\
\hline
\end{tabular}


(a) Plane of discontinuity: $c^{\prime}$ variable between $1 \mathrm{kPa}$ and $15 \mathrm{kPa} ; \phi^{\prime}=21 \cdot 5^{\circ}$.

(b) Clay above and below the critical plane: $c^{\prime}=65 \mathrm{kPa}$; $\phi^{\prime}=24^{\circ}$ (mass properties).

A drained cohesion, $15 \mathrm{kPa}$, was assumed to correspond to the initial phases, and $c^{\prime}=1 \mathrm{kPa}$ was a further reduction of cohesion for the subsequent phases.

This FE analysis also provided data relating to the evolution of pore water pressures in the foundation. Fig. 14 shows the distribution of pressures at the end of the calculation (just prior to rupture). Note the substantial influence of the heavy tailings and the very limited dissipation of pore pressures. A profile of water pressures along the future failure plane is shown in Fig. 15. The FE prediction is compared with the result of the elastic-consolidation analysis reported before. The correspondence is very good.

More detailed information on the very limited dissipation of pore water pressures that took place during construction is given in Fig. 16. This shows the calculated evolution of pore water pressures for a few points under the lagoon, under the embankment structure and downstream of the embankment toe. The magnitude of the pore pressure developed is basically controlled by the added weight placed above each of the points considered.

The analysis also confirms that the shear deformations accumulate on the potential failure plane, and they extend as the embankment construction advances (Fig. 17(a)). The rupture mechanism, identified by means of the mesh deformation (Fig. 17(b)), is similar to the actual failure mechanism described in the companion paper (Alonso \& Gens, 2006). The failure phase was induced by a final reduction of strength parameters. Fig. 17(b) shows the passive wedge developed at the distal end of the slide, and a classic

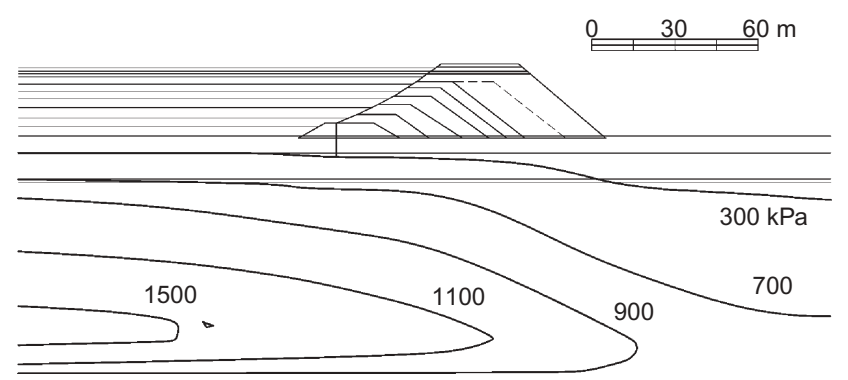

Fig. 14. Distribution of pore water pressures in last stage of FE calculations, immediately prior to failure

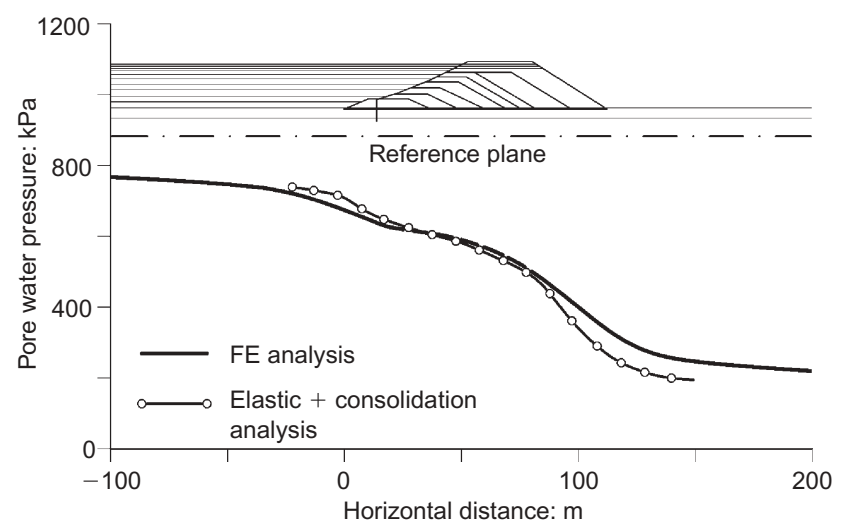

Fig. 15. Distribution of pore water pressures along failure surface (reference plane): comparison of $\mathrm{FE}$ and simplified elastic-consolidation analysis
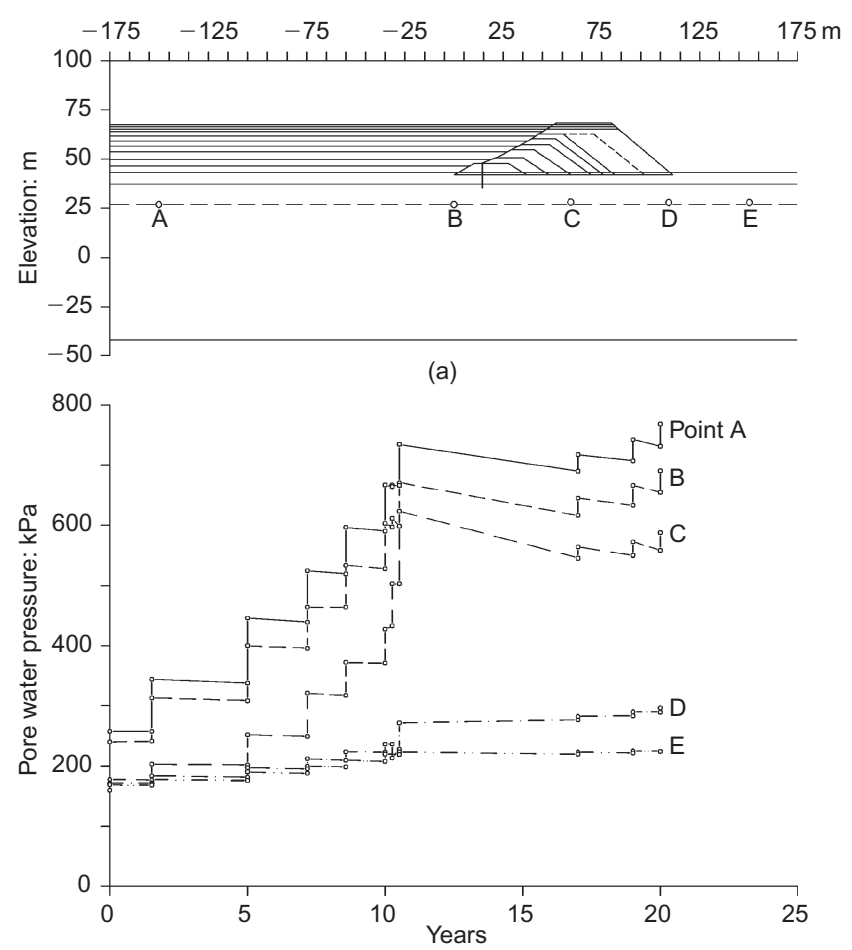

(b)

Fig. 16. Calculated development of pore water pressure at points of failure surface: FE analysis

upstream active wedge (the model did not include the vertical jointing existing in the clay unit).

The computed distributions of shear stresses on the failure plane at the end of the construction period are shown in Fig. 18 for the two cases analysed: M1, uniform strength $\left(c^{\prime}=\right.$ $65 \mathrm{kPa} ; \phi^{\prime}=24^{\circ}$ ); and M2, the case of a discontinuity with a reduced strength $\left(c^{\prime}=1 \mathrm{kPa} ; \phi^{\prime}=21 \cdot 5^{\circ}\right)$. The calculated shear stresses' profiles are similar in the two cases. But the real difference is clearly illustrated when the strength limits for both cases are considered. Those limits are also indicated in the figure. They have been calculated on the basis of the effective normal stresses against the failure plane and the corresponding strength parameters. When homogeneous matrix properties are considered, all the points remain within the strength limits, and failure cannot be explained. When a reduced strength is introduced, the excess shear stress has to be redistributed, increasing the length of the failure surface that lies at or very close to failure.

\section{EFFECT OF DIP AND ORIENTATION OF BEDDING PLANES}

Some aspects of the failure cannot be properly explained without paying attention to the effect of the clay structure. The failure mechanism should explain convincingly why the failure took place in the southern pyritic basin and not in the northern pyroclastic lagoon. Embankment conditions were similar in both cases, and the analysis presented in previous sections does not introduce any specific feature associated with the southern lagoon. If the clay is viewed as a layered material rather than as a homogeneous mass, a new perspective emerges. It transpires that bedding planes are oriented in a direction $\mathrm{N} 60^{\circ} \mathrm{E}$, and dip directions of the clay layers are aligned towards SSE. It is then easy to see that the orientation of the embankment in the north basin implies that the thrust of the tailings is close to the direction of the bedding planes. In other words, the apparent dip of the bedding planes is close to $0^{\circ}$. When the thrust against 

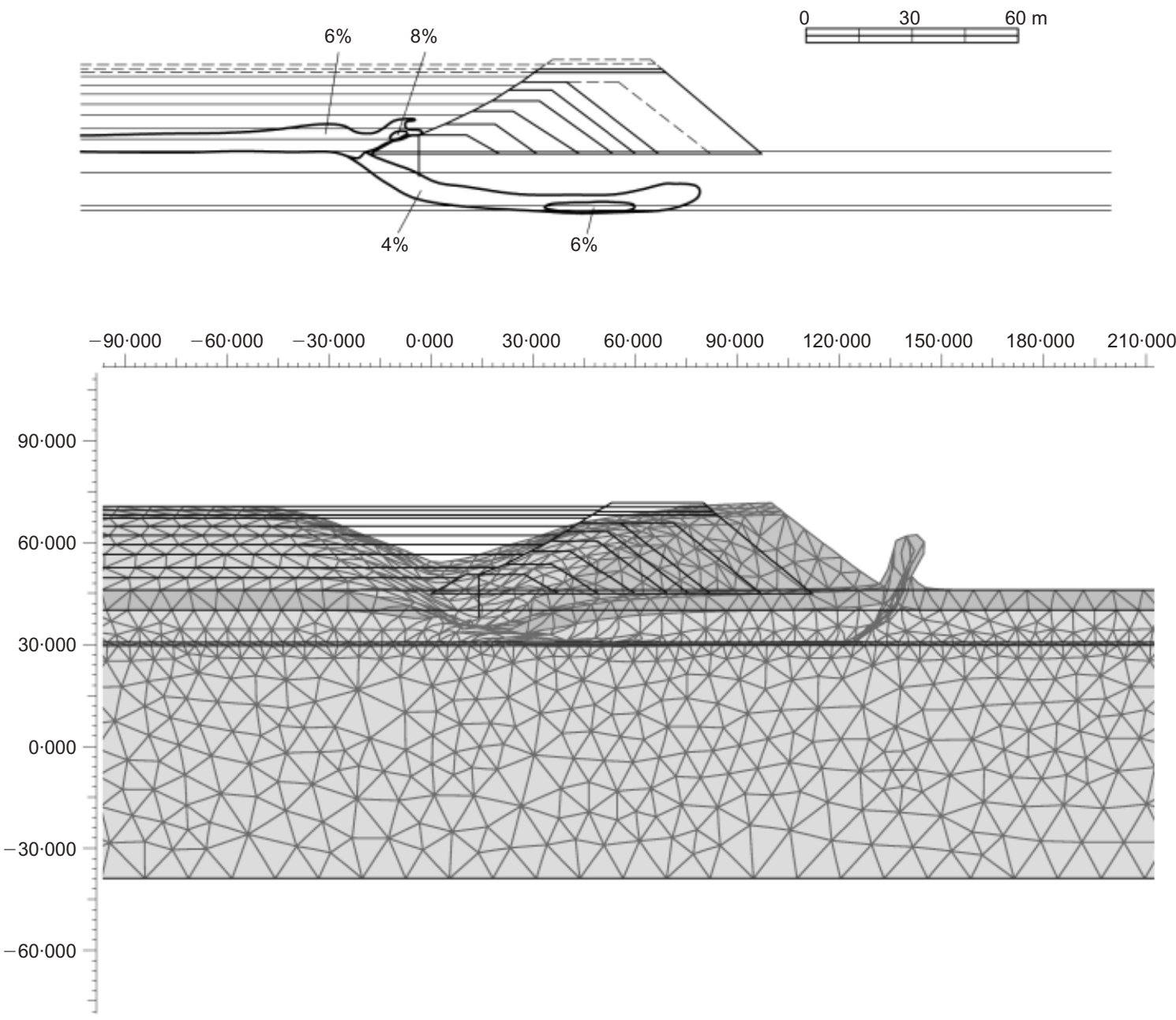

Fig. 17. (a) Contours of accumulated shear deformations from origin of calculations (maximum deformation 22.35\%); (b) mesh deformation during failure process. The figure shows the development of an active state in the tailings, upstream of the dam, and a passive wedge at the downstream toe. The former is not supported by observations but the position of the passive wedge, immediately downstream of the dam, is closer to real conditions. Horizontal coordinates start at the upstream toe

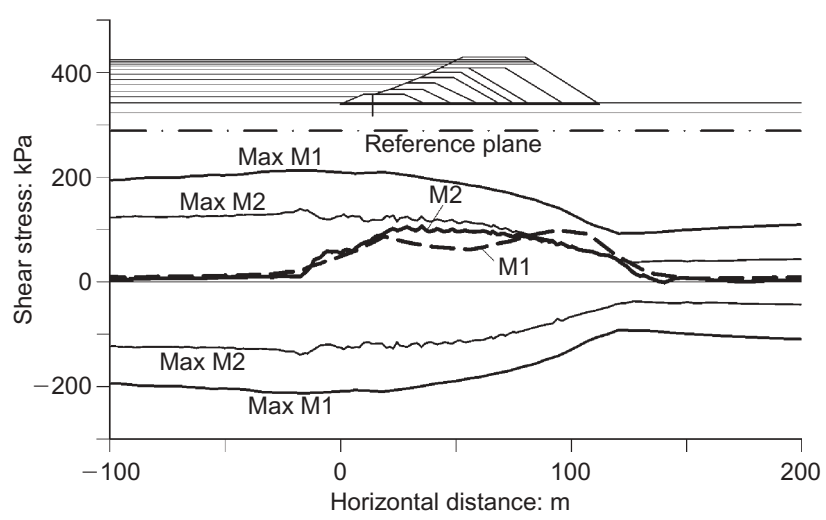

Fig. 18. Distribution of shear stresses along failure plane for two FE analyses performed. Horizontal coordinates start at upstream toe

the southern basin is considered, a different situation arises because of the change in direction (around $20^{\circ}$ ) of the embankment, and the thrust follows more closely the true dip of the bedding planes $\left(2^{\circ}\right)$.

It was argued previously (Alonso \& Gens, 2006) that this fact could explain why the failure took place in the southern basin. An additional field observation is consistent with the relevant role played by the orientation of bedding planes. The forward displacement of the embankment showed a change in orientation towards the south, which is interpreted as trying to follow the true dip of the bedding planes.

These effects are analysed using a simple three-dimensional interpretation of the slide. Consider in Fig. 19 a free body diagram showing a slice of the failed embankment sliding on the critical bedding plane. The following reference axes need to be considered: the apparent dip of $0^{\circ}$; the true dip; and the normal to the bedding plane. The external acting forces controlling the stability are also shown: the weight, $\bar{W}$, of the embankment (and the moving foundation soil) and the tailings' thrust $\left(\bar{E}_{1}\right.$ or $\left.\bar{E}_{2}\right) . \bar{W}$ has two components, $\bar{W}_{\mathrm{n}}$ and $\bar{W}_{\mathrm{s}}$, in the normal and tangential direction to the bedding planes. $\bar{E}_{1}$ corresponds to the southern basin, whereas $\bar{E}_{2}$ is the thrust direction in the northern lagoon. In both cases they are assumed to be normal to the embankment direction and parallel to the bedding planes. These forces are plotted in Fig. 19(b). If the resistance offered by the sliding plane is purely frictional (friction angle $\phi^{\prime}$ ), equilibrium in the sliding plane requires

$$
W_{\mathrm{n}}^{\prime} \tan \phi^{\prime}=\left|\bar{F}+\bar{W}_{\mathrm{s}}\right|
$$

where

$$
W_{\mathrm{n}}^{\prime}=W_{\mathrm{n}}-U=W \cos \alpha_{\mathrm{b}}-U
$$

and $\bar{F}$ is the thrust vector (either $\bar{E}_{1}$ or $\bar{E}_{2}$ ). $\alpha_{\mathrm{b}}$ is the true 


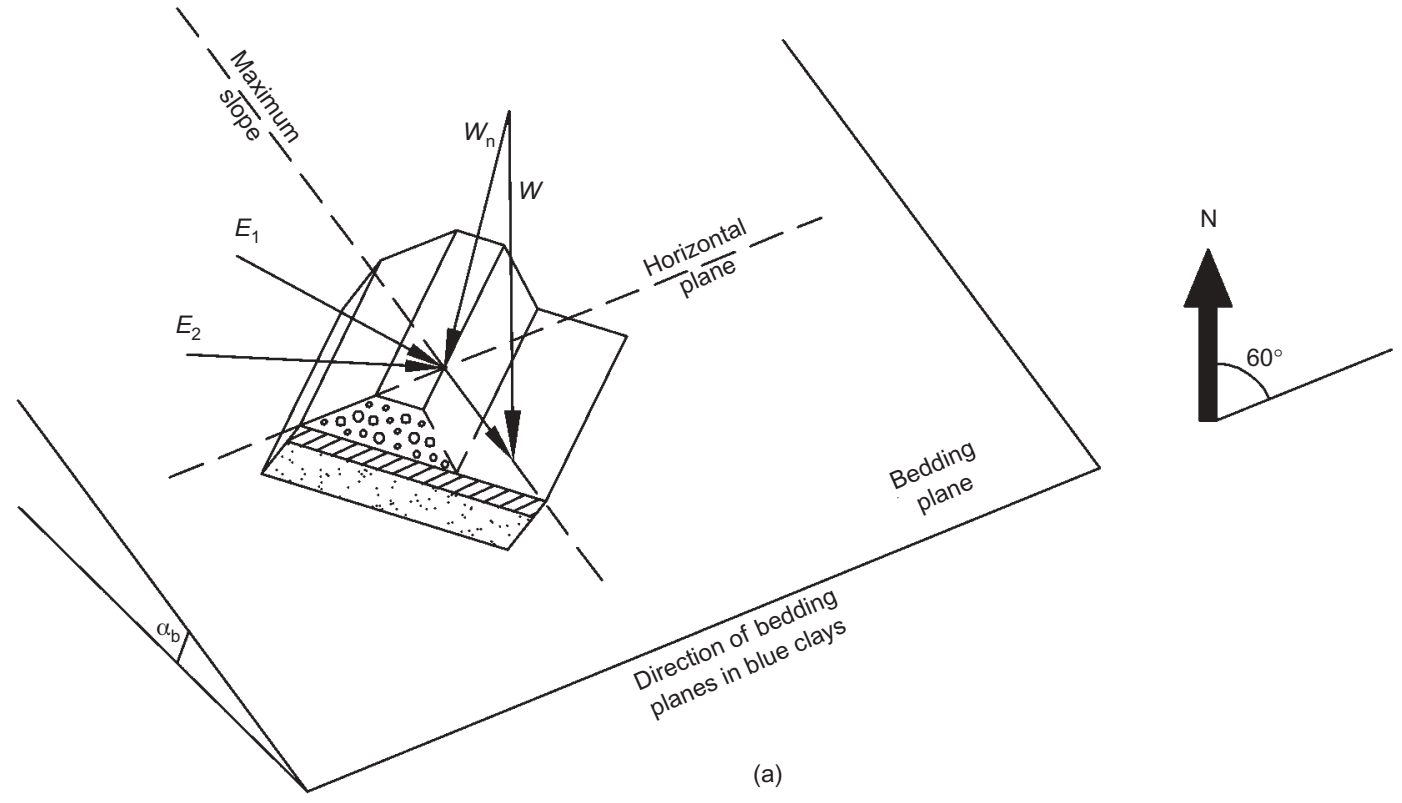

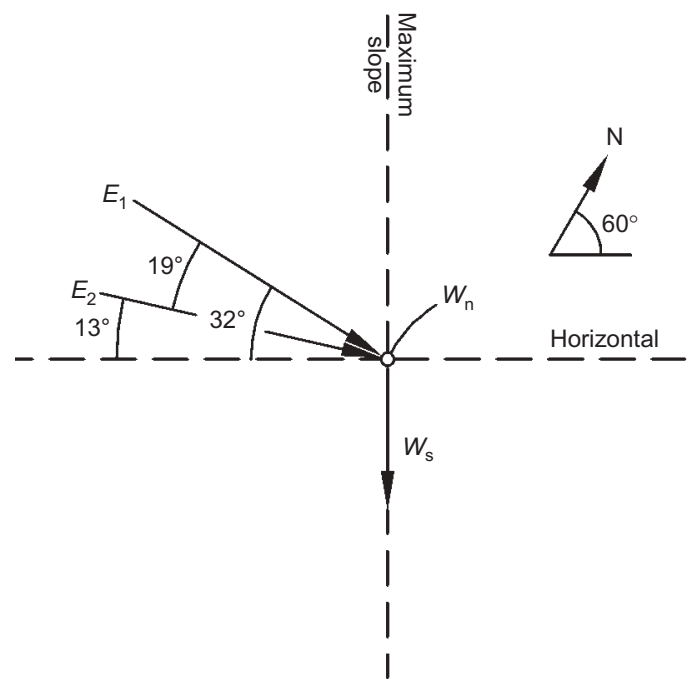

(b)

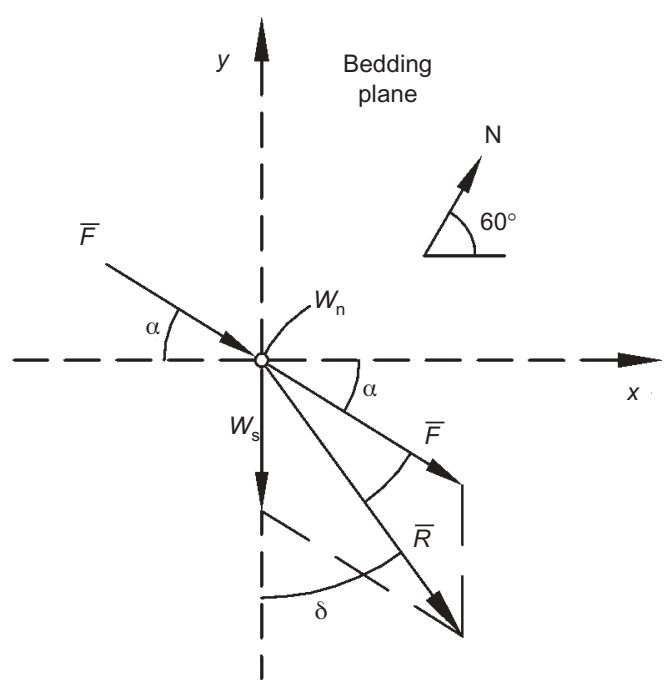

(c)

Fig. 19. (a) Three-dimensional scheme of slice of embankment sliding on a bedding plane; (b) forces acting on slice; (c) resultant force

dip angle. Equation (1) may be expanded in terms of the absolute value of the involved vectors to give

$$
F^{2}+2 F W \sin \alpha_{\mathrm{b}} \sin \alpha+W^{2} \sin ^{2} \alpha_{\mathrm{b}}-W_{\mathrm{n}}^{\prime 2} \tan ^{2} \phi^{\prime}=0
$$

where $\alpha$ is the orientation of the thrust force with respect to the horizontal line of bedding planes (see Fig. 19). Equation (3) provides the pushing force $F$ as a function of angle $\alpha$.

The direction of the motion may be also obtained. In equilibrium, and given that the sliding mechanism is purely frictional, the motion direction will follow the resultant disturbing force: $\bar{R}=\bar{F}+\bar{W}_{\mathrm{s}}$. The sliding direction is indicated, in Fig. 19, by angle $\delta$.

Equation (3) has been plotted in Fig. 20 as a polar diagram showing the variation of the force $F$ in equilibrium as a function of the direction of the force, defined by $\alpha$. The remaining variables in equation (3) (weight $W$, dip of strata $\alpha_{\mathrm{b}}=3^{\circ}$, water pressure resultant $U$, and friction angle $\phi^{\prime}=$ $11^{\circ}$ ) are known. Two directions are particularly relevant in Fig. 20: $\alpha=13^{\circ}$, representative of the northern embank- ment; and $\alpha=32^{\circ}$ for the southern basin. The corresponding forces for equilibrium are $5.27 \mathrm{MN} / \mathrm{m}$ and $4.11 \mathrm{MN} / \mathrm{m}$ respectively. In other words, if the tailings lagoon is pushing the embankment with an overall force of $4 \cdot 11 \mathrm{MN} / \mathrm{m}$, the southern embankment becomes unstable, whereas the northern embankment still has a 'safety factor' of 1.28 against sliding. This result makes it very unlikely that the northern embankment could have failed first. The displacement vectors, once sliding is initiated, are also plotted in Fig. 20. Note that they do not follow the direction of thrust but are directed towards the true dip direction of clay layers. This is consistent with observations of the sliding direction of the failed embankment. The force diagram plotted in Fig. 20 may also be interpreted as the macro yield locus for the sliding of the embankment on an inclined plane. The radius of the circle is the frictional resistance $(\mathrm{W}-\mathrm{U}) \tan \phi^{\prime}$. The yield circle is defined by displacing the purely frictional circle, valid for a horizontal plane, a distance $W \sin \alpha_{\mathrm{b}}$ in the direction of the maximum slope of the clay strata. In other words, the inclination of the strata results in a kinematic hardening in the direction of their maximum slope. The 


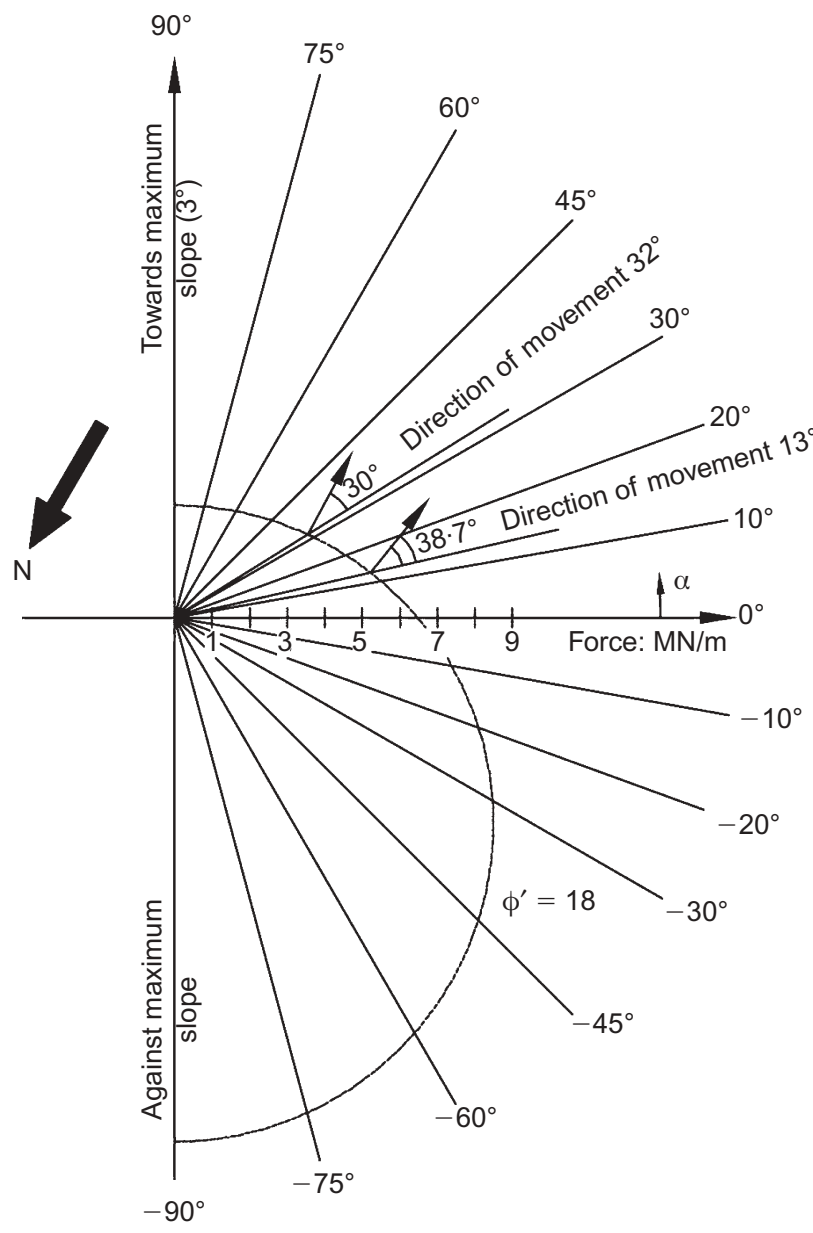

Fig. 20. Polar force diagram for equilibrium conditions

sliding direction is normal to the yield locus defined in this way, as shown also in Fig. 20.

\section{PROGRESSIVE FAILURE}

Progressive failure is identified in the previous analysis as one of the main phenomena leading to the failure of Aznalcóllar dam. In a number of classic contributions (Skempton, 1964; Terzaghi \& Peck, 1967; Bjerrum, 1967; Bishop, 1967, 1971) progressive failure was frequently mentioned as a mechanism leading to the instability of overconsolidated clays. Those authors suggested that the relevance of progressive failure increases in cases of nonuniform stress distributions (this is particularly the case of the downstream construction procedure of Aznalcóllar dam) and in clays with marked brittleness. A recent review of the subject has been presented by Jardine et al. (2004).

Palmer \& Rice (1973), Rice (1973) and Chowdhury (1978) have presented rigorous analyses of the propagation of rupture surfaces in idealised geometries. Numerical analyses were used in early attempts to model progressive failure as a procedure by which to derive realistic strength values, which are then used in a limit equilibrium analysis (Pariseau, 1972; Gates, 1972; Lo \& Lee, 1973). Recent significant contributions using the finite element method have been presented by Yoshida et al. (1991), Potts et al. (1990, 1997) and Dounias et al. (1996).

The issue of progressive failure is often associated with the concept of the 'fully softened strength' (Skempton, 1970, 1977), the strength obtained from tests on remoulded samples. It has also been observed that post-rupture strength envelopes (Burland, 1990) corresponding to the strength after bond breaking often lie close to the 'fully softened strength', but the reasons for this coincidence are unclear, and it may be fortuitous (Georgiannou \& Burland, 2001).

Stark \& Eid (1994) reviewed case histories involving firsttime slides in stiff fissured clays, reported the value of the mobilised strength at failure, and compared it with two strength values: the fully softened and the residual value. Such a comparison is shown in Fig. 21. It can be seen that in most instances the mobilised strength at failure lies about midway between the 'fully softened strength' and the residual strength.

However, it is doubtful that such a strength plays a real role in this type of failure (Bishop, 1967, 1971; Chandler, 1984; Jardine et al., 2004). The operational strength must be a function of peak, post-rupture and residual strength, the rate of strength degradation and the non-homogeneous patterns of strain development along the failure surface. A more useful parameter for characterising progressive failure is, therefore, the 'residual factor' defined by Skempton (1964) as

$$
R=\frac{\left(\bar{\tau}_{\mathrm{P}}-\bar{\tau}\right)}{\left(\bar{\tau}_{\mathrm{P}}-\bar{\tau}_{\mathrm{R}}\right)}
$$

$R$ measures the degree of development of residual strength along the failure surface. $\bar{\tau}_{\mathrm{P}}$ and $\bar{\tau}_{\mathrm{R}}$ are the average peak and residual strengths at the prevailing normal effective stress at collapse. Conventional limit equilibrium methods can be used to find $\bar{\tau}$ (which corresponds to the condition safety factor $=1$ ). Therefore, if mean peak and residual strength parameters have been determined, the value of $R$ can be derived from a back-analysis of an actual failure. Few detailed case histories that unambiguously demonstrate the existence of a case of progressive failure have been published. And, if the search is concentrated in failures associated with earth dams, the field information is even scarcer.

One of the relevant failures associated with progressive failure was the Selborne experiment and the interpretation of inclinometer data provided by Cooper (1996). The slope, which was forced to fail by increasing the pore water pressure, was located in weathered Gault high-plasticity clay $\left(w_{\mathrm{L}}=70-75 \%\right.$; IP $=22 \%$; clay fraction $\left.=34-48 \%\right)$. Yielding was shown to start at the toe of the slope, and it progressed upwards, as predicted also by the more recent finite element analysis of delayed failure of excavated slopes in brittle clay (Potts et al., 1997). Based on the data provided by Cooper (1996) it is possible to calculate a value of $R=0.75$.

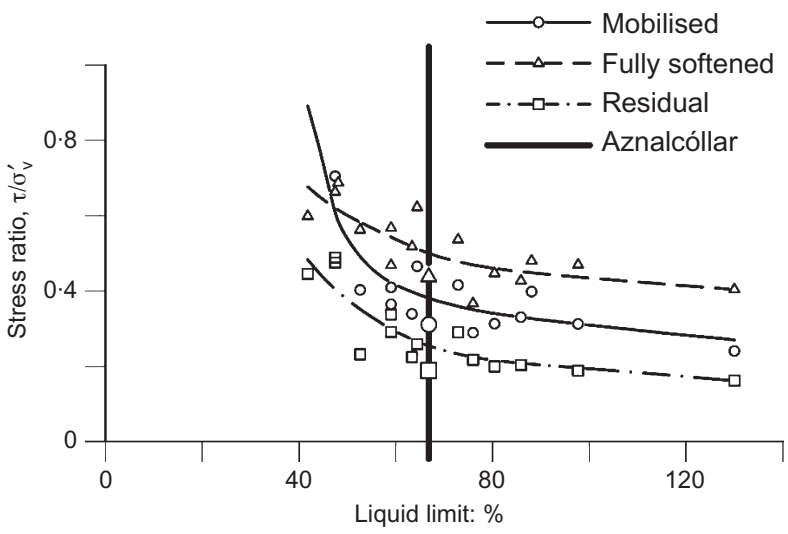

Fig. 21. Mobilised, fully softened and residual stress ratio for field case histories (Stark \& Eid, 1994). Also plotted are calculated values for Aznalcóllar failure 
A case analysed in more detail is the Carsington dam failure (Skempton, 1985; Potts et al., 1990). In the analysis reported by Potts et al. (1990), some brittleness was assigned to the two clay materials directly involved in the failure: the compacted core (a high-plasticity clay: $w_{\mathrm{L}}=74 \% ; w_{\mathrm{P}}=$ $32 \%$; clay fraction $=62 \%$ ) and the natural yellow clay (an oxidised mudstone having $w_{\mathrm{L}}=79 \% ; w_{\mathrm{P}}=34 \%$; clay fraction $=64 \%$ ). The core was assumed to behave in undrained conditions, and its strength changed between a peak value of $42 \mathrm{kPa}$ to a residual value of $30 \mathrm{kPa}$. For the yellow clay, peak and residual drained parameters were based on laboratory tests $\left(c_{\mathrm{p}}^{\prime}=6 \mathrm{kPa} ; \phi_{\mathrm{p}}^{\prime}=19^{\circ} ; c_{\mathrm{r}}^{\prime}=0 ; \phi_{\mathrm{r}}^{\prime}\right.$ $\left.=12^{\prime}\right)$. The yielding is described as commencing at the core and upstream 'boot' at a relatively early stage and progressing towards the slope toe. The argument in favour of progressive failure is based on a comparison between some field observations and calculation results. The evidence of progressive failure is also supported by conventional limit equilibrium results, which predict a safety factor of 1.41 if based on peak strengths, and 1.21 if based on critical state parameters (Vaughan, 1989). However, it should be added that intermittent shear surfaces existed at the base of the yellow clay. Therefore the available initial in situ strength in the yellow clay layer was substantially lower than the peak. The Skempton 'residual factor' defined above was found by Potts et al. (1990) to be $R=0.42$ in the core and $R=0.52$ in the yellow clay. These values suggest that an appropriate strength for slope stability calculations based on limit equilibrium techniques is the average between peak and residual values.

Additional evidence of progressive failure in cut slopes in stiff clays is provided by Potts et al. (1997). The analysis, in this case, incorporates the coupling between pore pressure generation and dissipation, and the mechanical response of the strain-softening clay. Rupture surfaces for a $10 \mathrm{~m}$ high $3: 1$ slope, selected as a computational example, were shown to start at the toe of the slope and to progress upward as the pore water pressures evolve in the vicinity of the strained failure surface. Similarities with observations of actual delayed collapse of cut slopes highlight the relevance of progressive failure mechanisms in these cases. The value of $R$ depends on many factors (constitutive behaviour, geometry of the case, stress and kinematic constraints), but the calculated values $(R=0 \cdot 5-0 \cdot 6)$ are similar to previously reported values for failures of cuttings in Brown London Clay. As the analyses did not incorporate drained peak cohesion, the indicated values for $R$ imply that the mobilised friction angle at failure is close to the average between the tangents of peak and residual friction angles. From this point of view, this is consistent with the calculated values of $\phi_{\text {mob }}^{\prime}$ reported by Stark \& Eid (1994).

The results obtained for the Aznalcóllar embankment yield a value of $R$ approximately equal to 0.76 if the peak strength of the intact material is considered. However, if the failure initiated along a bedding plane, the post rupture strength may be more relevant as the initial strength of the material. In that case, the mobilised friction angle $\left(\phi_{\mathrm{mob}}^{\prime}=\right.$ $17^{\circ}$ ) lies approximately half way between the post-rupture friction value $\left(\phi_{\mathrm{p}}^{\prime}=24 \cdot 1^{\circ}\right)$ and the residual value $\left(\phi_{\mathrm{r}}^{\prime}=\right.$ $11^{\circ}$ ). Therefore the value of $R$ is 0.46 . The post-rupture, mobilised and residual stress ratios have also been plotted in the graph published by Stark \& Eid (1994) in Fig. 21, for the corresponding liquid limit of the Guadalquivir blue clay (identifying for this purpose post-rupture strength with fully softened strength). One should be careful, however, in accepting it as a well-established fact that this average can be used in design, as a number of case-specific factors, already mentioned, control the development of progressive failure.

\section{DISCUSSION AND CONCLUDING REMARKS}

The blue Guadalquivir carbonated clay has features that are found in clayey soils and rocks. It maintains a definite structural pattern of post-depositional joints, and the subhorizontal layering introduces a dense system of highly continuous planes. This structural network was evident in the large blocks of foundation clay transported by the fluidised current of tailings and deposited in the flooded plain of the Agrio river, downstream from the breach (Alonso \& Gens, 2006). Some aspects of the failure are properly interpreted if this clay structure is taken into account. In particular, the basal sliding plane was essentially located along a bedding plane. The strength available on this plane is the key property to explain the failure.

The stability analysis performed (finite elements) indicates that the measured average peak strength properties of the clay do not lead to the initiation of yield conditions in any point of the clay foundation. It is implied that some strength loss was initially present along the bedding planes. The amount and distribution of the associated reduction of available strength of the bedding planes are not known. Field evidence showing the existence of striated bedding surfaces has been found, but the soil investigation performed also indicates that bedding planes were difficult to find. In fact, an engineering interpretation of the borehole records and specimen descriptions would imply a fairly homogeneous and intact massive deposit of clay. Under these conditions, conventional stability calculations predict a rotational failure mode, which was clearly not the case.

The failure was clearly controlled by particular surfaces, and this implies that the analysis should concentrate on the available pore water pressures and drained strength properties along the critical planes. It has been argued that the strength had an original reduced strength if compared with the matrix peak strength. The subsequent evolution of clay straining, as the dam was built in a downstream manner and the level of heavy tailings increased, led to a progressive reduction of available strength. The effective cohesive term is lost first, as suggested by the interpretation given to the results of drained direct shear strength tests (Alonso \& Gens, 2006). Thereafter, the failure surface behaves as a frictional contact whose friction coefficient reduces towards an ultimate residual value when the clay structure is oriented in the direction of sliding.

The failure is explained by an average friction angle of the sliding basal plane of $\phi^{\prime}=17-18^{\circ}$ (and no cohesion). This value is lower than the average peak friction measured in direct shear tests $\left(24 \cdot 1^{\circ}\right)$ and corresponds to an average friction intermediate between the peak intact or remoulded friction and the residual friction angle $\left(\phi_{\text {res }}^{\prime}=11^{\circ}\right)$. As with other sliding failures in brittle clays, a residual factor close to $R=0 \cdot 5$ seems to apply in the case of Aznalcóllar dam.

No specific consideration of peak, remoulded or residual conditions was made at the design stage. The drained friction angle of the clay used in design $\left(\phi^{\prime}=25^{\circ}\right)$ was derived directly from some consolidated undrained triaxial tests that exhibited a very moderate peak behaviour, probably as a consequence of the disturbance induced during sampling operations.

The reduction of available strength due to progressive failure is, however, far from explaining the failure, because of the conservative assumptions adopted in design calculations: tailings were assumed to be liquefied, and pseudostatic horizontal and vertical accelerations were introduced.

Pore water pressures were conventionally taken as given by a steady-state flow net, a common practice in dam design. In addition, the water levels measured in open pipes located under the dam in 1996 were taken as an indication of a general phreatic surface located within the surface 


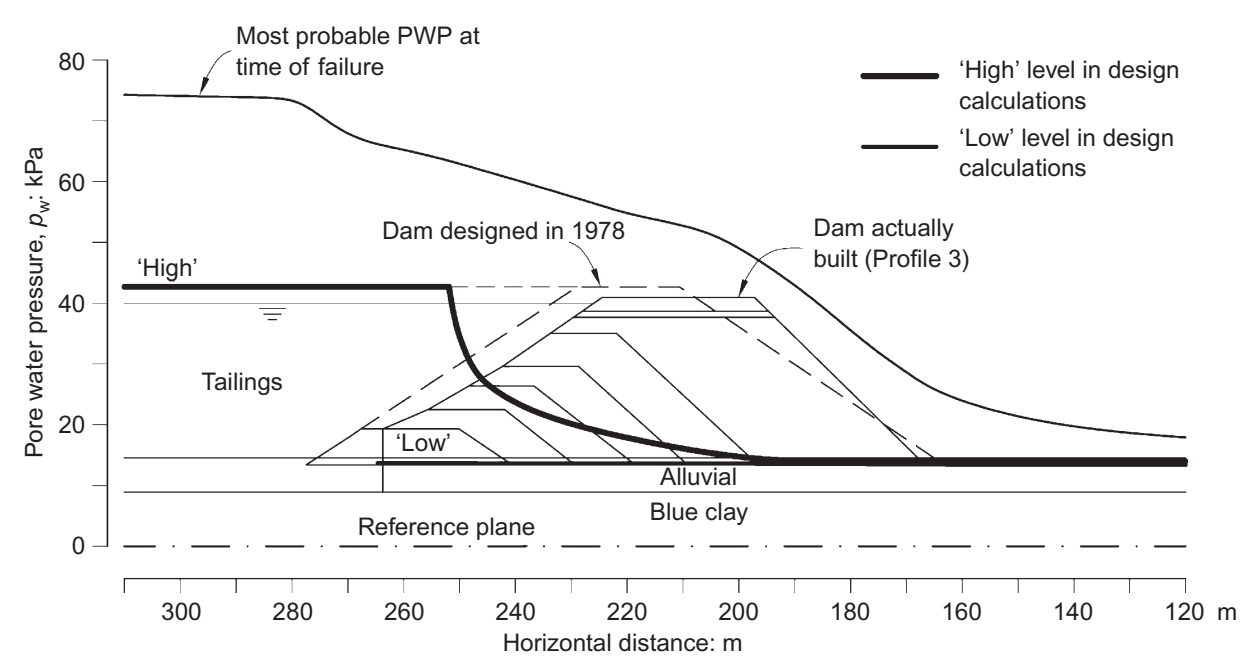

Fig. 22. Phreatic surface used in design calculations and best estimate of pore water pressure existing on sliding plane at time of failure

granular terrace layer. Limit equilibrium calculations using this phreatic level indicated a safety factor against downstream sliding of 1.40 for the dam configuration existing in 1998 ( $27 \mathrm{~m}$ above ground level). The two phreatic levels used in design calculations are compared in Fig. 22 with the best estimate of water pressures prevailing on the sliding surface at the time of the failure.

The steady-state flow conditions are irrelevant in this case, given the low permeability of the clay foundation. The slow dissipation of pore water pressures is also a consequence of the considerable homogeneity of the clay, in terms of permeability. No pervious seams or structural discontinuities helped to dissipate excess pore water pressures. The joints and bedding surfaces are not conductive features. Remarkably, the consolidation coefficient derived from field observations of pore water pressure gradients is very similar in this case to the coefficient of consolidation derived from the back-analysis of the consolidation behaviour of small specimens. The average degree of dissipation of pore water pressures after 20 years of continuous increase of the dam height is no more than $15 \%$.

A final point relates to the slopes of the rockfill dam. They were designed to be $27.8^{\circ}$ and $29.9^{\circ}$ (upstream and downstream respectively). The downstream slope was increased to $39^{\circ}$ around 1985 , and it was maintained constant thereafter. The increase in slope reduced the safety of the dam and extended the damage associated with progressive failure. It has been shown that the geometry of the advancing dam and the parallel partial dissipation of pore water pressures generate a critical position for the maximum of shear stress ratios. These critical points, combined with the downstream construction method used, seem to define the position of the rupture surface. A (hypothetical) new design of the dam would certainly require a significant reduction of the downstream slope, in order to maintain the induced shear stress ratios below the existing strength on the bedding surfaces.

\footnotetext{
NOTATION

$c^{\prime}$ effective cohesion

$c_{\mathrm{p}}^{\prime}$ peak effective cohesion

$c_{\mathrm{v}}$ coefficient of consolidation

$e$ void ratio

$E_{1} \quad \bar{F}$ for southern position of perimeter dam

$E_{2} \quad F$ for northern position of perimeter dam

$F$ absolute value of $F$
}

$\bar{F}$ tailings thrust against slice of failed dam

$R \quad\left[=\left(\bar{\tau}_{\mathrm{p}}-\bar{\tau}\right)\left(\bar{\tau}_{\mathrm{p}}-\bar{\tau}_{\mathrm{R}}\right)\right]$ residual factor defined by Skempton (1964)

$\bar{R} \quad\left(=\bar{F}+\bar{W}_{s}\right)$ disturbing force acting on the slice of failed dam

SF safety factor

$S_{\mathrm{r}}$ degree of saturation

$V$ water pressure force on basal sliding plane

$W$ absolute value of $\bar{W}$

$W_{\mathrm{n}}$ absolute value of $\bar{W}_{\mathrm{n}}$

$W_{\mathrm{n}}^{\prime} \quad W_{\mathrm{n}}-V$

$\bar{W}$ weight of a slice of the failed dam and the accompanying foundation soil (vector in the direction of gravity)

$\bar{W}_{\mathrm{n}}$ normal component of $\bar{W}$ in direction normal to basal sliding plane

$\bar{W}_{\text {s }}$ Shear component of $\bar{W}$ in direction of basal sliding plane

$\alpha$ angle between direction of thrust and bedding plane direction

$\alpha_{\mathrm{b}} \quad$ dip angle of bedding plane

$\gamma_{\mathrm{s}} \quad$ unit weight of solids

$\gamma_{\mathrm{w}}$ unit weight of water

$\sigma_{\mathrm{n}}^{\prime} \quad$ effective normal stress

$\tau$ shear stress

$\bar{\tau}$ average shear stress at failure along sliding surface

$\bar{\tau}_{\mathrm{p}}$ average peak strength along sliding surface

$\bar{\tau}_{\mathrm{r}} \quad$ average residual strength along sliding surface

$\phi_{\mathrm{mob}}^{\prime} \quad\left(=\tau / \sigma_{\mathrm{n}}^{\prime}\right)$ mobilised friction angle

$\phi^{\prime}$ effective friction angle

$\phi_{\mathrm{p}}^{\prime}$ peak effective friction angle

$\phi_{\mathrm{r}}^{\prime}$ effective residual friction angle

\section{REFERENCES}

Alonso, E. E. \& Gens, A. (2006). Aznalcóllar dam failure. Part 1: Field observations and material properties. Géotechnique 56, No. 3, 165-183.

Bishop, A. W. (1967). Progressive failure: with special reference to the mechanism causing it. Proceedings of the geotechnical conference on shear strength properties of natural soils and rock, Oslo, Vol. 2, pp. 142-150.

Bishop, A. W. (1971). The influence of progressive failure on the method of stability analysis. Géotechnique 21, No. 2, 168-172.

Bjerrum, L. (1967). Progressive failure in slopes of over-consolidated plastic clays and clay shales. J. Soil Mech. Found. Div. ASCE 93, SM5, 3-49.

Burland, J. B. (1990). On the compressibility and shear strength of natural clays. Géotechnique 40, No. 3, 329-378.

Chandler, R. J. (1984). Recent European experience in landslides in overconsolidated clays and soft rocks. Proc. 4th Int. Symp. on Landslides, Toronto 2, 19-25.

Chowdhury, R. N. (1978). Slope analysis. Amsterdam: Elsevier.

Cooper, M. R. (1996) The progressive development of a failure slip 
surface in over-consolidated clay at Selborne, UK. Proc. 7th Int. Symp. on Landslides, Trondheim 2, 683-688.

Dounias, G. T., Potts, D. M. \& Vaughan, P. R. (1996). Analysis of progressive failure and cracking in old British dams. Géotechnique 46, No. 4, 621-640.

Gates, R. H. (1972). Progressive failure model for clay shale. In Applications of the finite element method in geotechnical engineering (ed. C. S. Desai), pp. 327-347. Vicksburg, Miss.: US Army Engineers Waterways Experimental Station.

Georgiannou, V. N. \& Burland, J. B. (2001). A laboratory study of post-rupture strength. Géotechnique 51, No. 8. 665-675.

Jardine, R. J., Gens, A., Hight, D. W. \& Coop, W. R. (2004). Developments in understanding soil behaviour. In Advances in geotechnical engineering: The Skempton Conference (eds R. J. Jardine, D. M. Potts \& K. G. Higgins), Vol. 1, pp. 103-206. London: Thomas Telford.

Lo, K. Y. \& Lee, C. E. (1973). Stress analysis and slope stability in strain softening materials. Géotechnique 23, No. 1, 1-11.

Palmer, A. C. \& Rice, J. R. (1973). The growth of slip surfaces in the progressive failure of over-consolidated clay. Proc. R. Soc. London Ser. A 332, 527-548.

Pariseau, W. G. (1972). Elastic-plastic analysis of pit slope stability. In Applications of the finite element method in geotechnical engineering (ed. C. S. Desai, pp. 349-384. Vicksburg, Miss.: US Army Engineers Waterways Experimental Station.

Potts, D. M, Dounias, G. T. \& Vaughan, P. R. (1990). Finite element analysis of progressive failure of Carsington embankment. Géotechnique 40, No. 1, 79-101.

Potts, D. M., Kovacevic, N. \& Vaughan, P. R. (1997). Delayed collapse of cut slopes in stiff clay. Géotechnique 47, No. 5, 953-982.
Poulos, H. G. \& Davis, E. H. (1974). Elastic solutions for soil and rock mechanics. New York: Wiley.

Rice, J. R. (1973). The initiation and growth of shear bands. Proceedings of the symposium on plasticity and soil mechanics, Cambridge, pp. 263-274.

Skempton, A. W. (1964). Long term stability of clay slopes. Géotechnique 14, No. 2, 77-101.

Skempton, A. W. (1970). First-time slides in over-consolidated clays. Géotechnique 20, No. 3, 320-324.

Skempton A. W. (1977). Slope stability of cuttings in brown London Clay. Proc. 9th Int. Conf. Soil Mech. Found. Engng, Tokyo 3, 261-270.

Skempton, A. W. (1985). Geotechnical aspects of the Carsington Dam failure. Proc. 11th Int. Conf. Soil Mech. Found. Engng, San Francisco 5, 2581-2591.

Stark, T. D. \& Eid, H. T. (1994). Slope stability analyses in stiff fissured clays. J. Geotech. Geoenviron. Engng 123, No. 4, $335-343$

Terzaghi, K. \& Peck, R. B. (1967). Soil mechanics in engineering practice. New York: Wiley.

Vaughan, P. R. (1989). Rotura de una presa de tierra instrumentada. In Instrumentación de Obras (eds E. E. Alonso and A. Gens), pp. 419-452. Barcelona: Ediciones UPC.

Vaughan, P. R. (1994). Assumption, prediction and reality in geotechnical engineering. Géotechnique 44, No. 4, 573-609.

Vaughan, P. R. \& Walbancke, H. J. (1973). Pore pressure changes and delayed failure of cutting slopes in overconsolidated clay. Géotechnique 23, No. 4, 531-539.

Yoshida, N., Morgenstern, N. R. \& Chan, D. H. (1991). Finite element analysis of softening effects in fissured, overconsolidated clays and mudstones. Can. Geotech. J. 28, No. 1, 51-61. 